\title{
Community-based HIV treatment service delivery model for female sex workers in Tanzania: Evaluation findings
}

\author{
Lung Vu \\ Population Council \\ Waimar Tun \\ Population Council \\ Louis Apicella \\ Population Council \\ Jeremiah Kidola \\ Caterina Casalini
}

See next page for additional authors

Follow this and additional works at: https://knowledgecommons.popcouncil.org/departments_sbsr-hiv

Part of the Demography, Population, and Ecology Commons, Family, Life Course, and Society Commons, Gender and Sexuality Commons, Immune System Diseases Commons, International Public Health Commons, and the Medicine and Health Commons How does access to this work benefit you? Let us know!

\section{Recommended Citation}

Vu, Lung, Waimar Tun, Louis Apicella, Jeremiah Kidola, Caterina Casalini, Gasper Mbita, Neema Makyao, Todd Koppenhaver, and Erick Mlanga. 2020. "Community-based HIV treatment service delivery model for female sex workers in Tanzania: Evaluation findings," Project SOAR Final Report. Washington, DC:

Population Council. 


\section{Authors}

Lung Vu, Waimar Tun, Louis Apicella, Jeremiah Kidola, Caterina Casalini, Gasper Mbita, Neema Makyao, Todd Koppenhaver, and Erick Mlanga 
Community-based HIV Treatment Service Delivery Model for Female Sex Workers in Tanzania: Evaluation findings

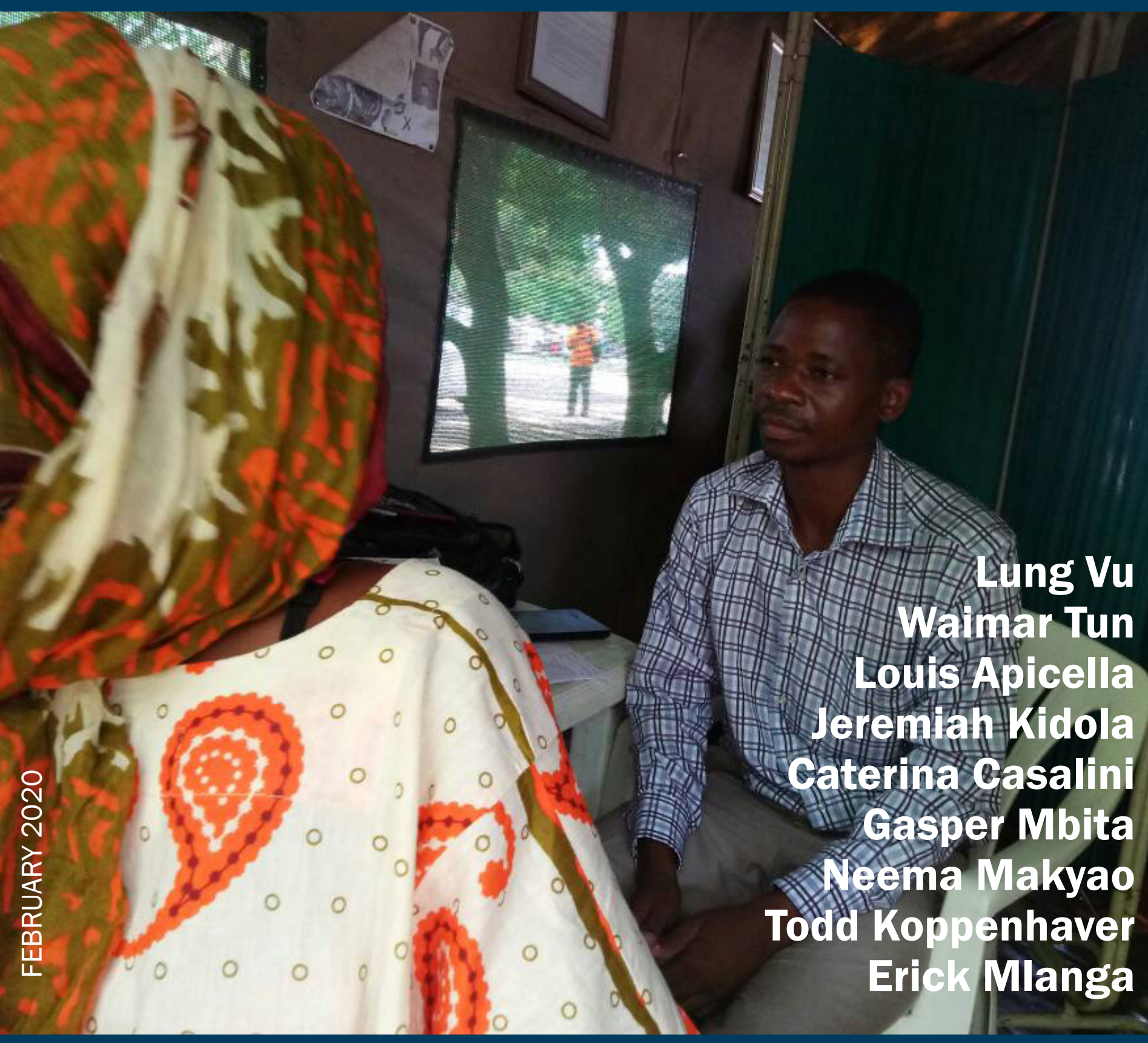

UsAID

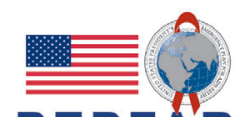

12

(b)

Sautiti

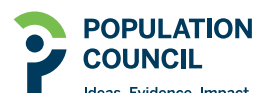

YSOAR 
Project SOAR

Population Council

4301 Connecticut Ave, NW, Suite 280

Washington, D.C. 20008 USA

Tel: +12022379400

Fax: +1 2022378410

projsoar.org

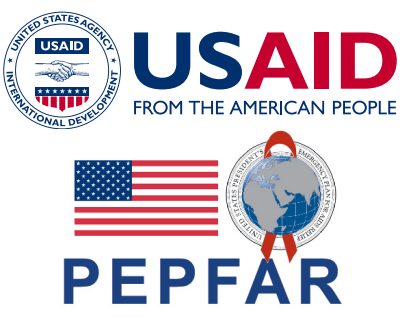

Project SOAR (Cooperative Agreement AID-OAA-A-14-00060) is made possible by the generous support of the American people through the United States President's Emergency Plan for AIDS Relief and the United States Agency for International Development (USAID). The contents of this guidance document are the sole responsibility of Project SOAR and the Population Council and do not necessarily reflect the views of USAID or the United States Government.

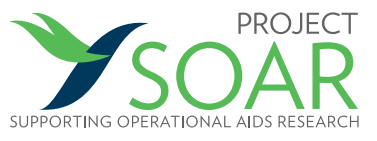

Through operations research, Project SOAR will determine how best to address challenges and gaps that remain in the delivery of HIV and AIDS care and support, treatment, and prevention services. Project SOAR will produce a large, multifaceted body of high-quality evidence to guide the planning and implementation of HIV and AIDS programs and policies. Led by the Population Council, Project SOAR is implemented in collaboration with Avenir Health, Elizabeth Glaser Pediatric AIDS Foundation, Johns Hopkins University, Palladium, and The University of North Carolina.

The Population Council confronts critical health and development issues-from stopping the spread of HIV to improving reproductive health and ensuring that young people lead full and productive lives. Through biomedical, social science and public health research in about 50 countries, the Council works with our partners to deliver solutions that lead to more effective policies, programs, and technologies to improve lives worldwide. Established in 1952 and headquartered in New York, the Council is a nongovernmental, nonprofit organization with an international board of trustees.

Front cover photo credit: CCSK RESEARCH SOLUTIONS

Published in February 2020. (C2020 The Population Council, Inc.

Suggested citation: Vu, Lung, Waimar Tun, Louis Apicella, Jeremiah Kidola, Caterina Casalini, Gasper Mbita, Neema Makyao, Todd Koppenhaver, and Erick Mlanga. 2020. "Community-based HIV treatment service delivery model for female sex workers in Tanzania: evaluation findings," Project SOAR Final Report. Washington, D.C.: Population Council. 


\section{Community-based HIV Treatment Service Delivery Model for Female Sex Workers in Tanzania: Evaluation findings}

Lung $\mathrm{Vu}^{1}$, Waimar Tun ${ }^{1}$, Louis Apicella ${ }^{2}$, Jeremiah Kidola ${ }^{3}$, Caterina Casalini ${ }^{4}$, Gasper Mbita ${ }^{4}$, Neema Makyao ${ }^{5}$, Todd Koppenhaver ${ }^{6}$, and Erick Mlanga ${ }^{6}$

${ }^{1}$ HIV and AIDS Program, Population Council, Washington, DC, USA

${ }^{2} \mathrm{HIV}$ and AIDS Program, Population Council, Tanzania

${ }^{3}$ National Institute for Medical Research, Mwanza, Tanzania

4Jhpiego, Tanzania

${ }^{5}$ National AIDS Control Program, Ministry of Health, Community Development, Gender, Elderly and Children, Tanzania

${ }^{6}$ United States Agency for International Development, Tanzania 


\section{ACKNOWLEDGMENTS}

We greatly appreciate the collaboration with our former and current Jhpiego/Sauti Programme colleagues (Albert Komba, Hally Mahler) who co-designed the community-based ART model; and Denis Bikaru, Aggrey Kasalama, all the clinicians, counselors, and peer educators who led the implementation of the pilot. We would like to acknowledge the hard work of the field research coordinators, Catherine Bunga and Erick Mgina; the data manager, Charles Mangya; and the laboratory supervisor, Eric Lyimo from NIMR, Mwanza Research Centre. This study would not be possible without the support of Tanzania's National AIDS Control Programme, which provided technical support, recommendations, and government buy-in for this study, as well as the Njombe Regional Health Medical Team, which provided objective and supportive supervision of the service activities. Lastly, we would like to thank the study participants for their willingness to participate and lead the way for the future of ART in Tanzania. 


\section{TABLE OF CONTENTS}

ACKNOWLEDGMENTS............................................................................................................ ii

ACRONYMS................................................................................................................................ iv

EXECUTIVE SUMMARY ..............................................................................................................

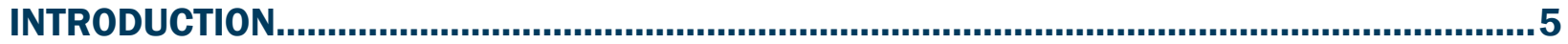

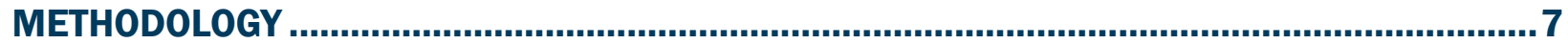

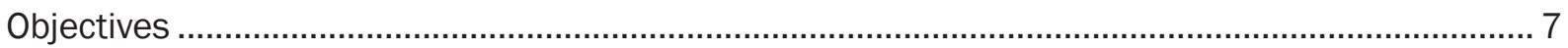

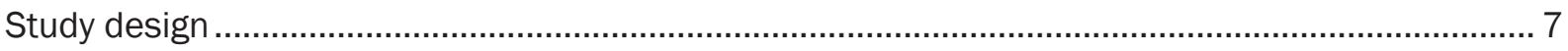

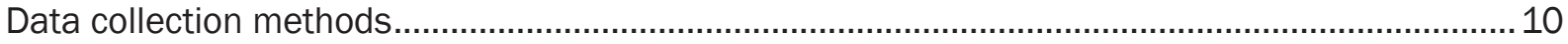

KEY FINDINGS ................................................................................................................... 14

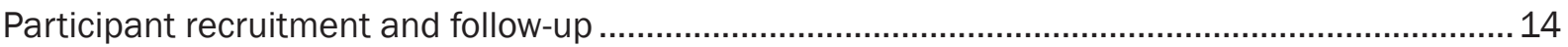

Effectiveness of the intervention on improving HIV treatment outcomes....................................... 17

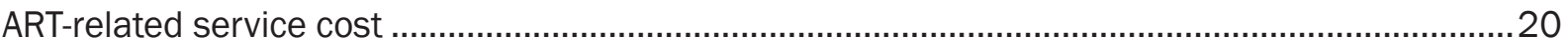

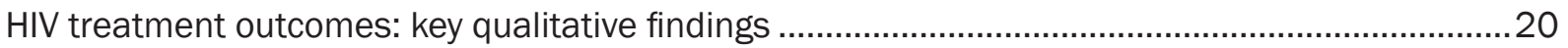

Effect of the intervention on sexual risk and violence................................................................26

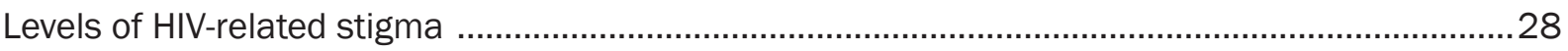

DISCUSSION

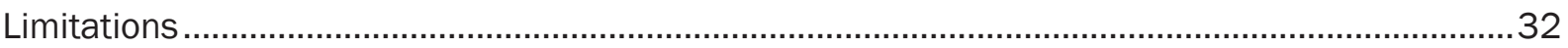

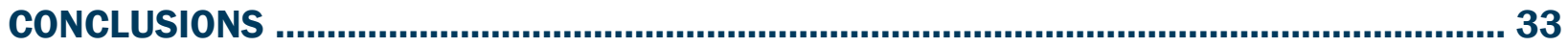

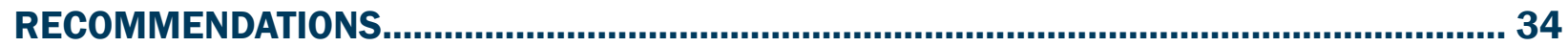

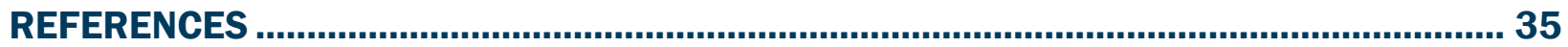

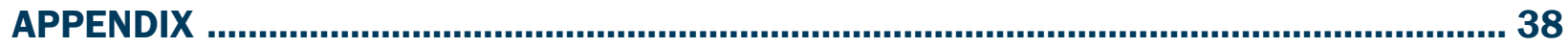




\section{ACRONYMS}

$\begin{array}{ll}\text { ART } & \text { Antiretroviral therapy } \\ \text { ARV } & \text { Antiretroviral } \\ \text { CBHTC } & \text { Community-based HIV testing and counseling services } \\ \text { CBHTC+ } & \text { Community-based HIV testing and counseling services plus } \\ \text { CTC } & \text { Care and treatment clinics } \\ \text { DBS } & \text { Dried blood spot } \\ \text { FSW } & \text { Female sex worker } \\ \text { HIV } & \text { Human immunodeficiency virus } \\ \text { HTC } & \text { HIV testing and counseling } \\ \text { IDI } & \text { In-depth interview } \\ \text { LTFU } & \text { Lost to follow-up } \\ \text { NACP } & \text { National AIDS Control Programme } \\ \text { OI } & \text { Opportunistic infection } \\ & \text { Sexually transmitted infection } \\ \text { TH } & \text { Tuberculosis } \\ \text { L } & \end{array}$




\section{EXECUTIVE SUMMARY}

Globally, female sex workers (FSWs) living with HIV have sub-optimal usage of antiretroviral treatment (ART); approximately 38 to 52 percent of FSWs living with HIV are on treatment (Mountain et al. 2014; Lancaster et al. 2016; Schwartz et al. 2017). Research in Tanzania has documented the challenges FSWs face in accessing HIV care and treatment services, including out-of-pocket costs associated with care, reaching distant clinics, lack of awareness and misperceptions of treatment, and dual stigma associated with sex work and HIV (Tomori et al. 2014).

To address these challenges, Project SOAR in collaboration with the National AIDS Control Program of the Government of Tanzania, National Institute of Medical Research, and Jhpiego's Sauti Program, conducted an implementation science study to investigate the delivery of community-based ART services to FSWs in Tanzania. Studies from sub-Saharan Africa have shown improved HIV treatment outcomes, such as uptake of HIV services, retention in care, and increased dignity and quality of life, by using community-based delivery of HIV services (Bemelmans et al. 2014; Govindasamy et al. 2014; Sharma et al. 2015; Suthar et al. 2013). The study assessed the effectiveness of the community-based ART delivery intervention in improving HIV treatment outcomes among FSWs in Tanzania.

\section{METHODOLOGY}

The study used a quasi-experimental prospective study design and aimed to investigate the effectiveness of a community-based model of ART delivery whereby ART provision was delivered at mobile community-based HIV testing and counseling services (CBHTC) and by home visits. Primary outcomes included:

- Proportion of individuals who are linked to care and initiate ART treatment (i.e., treatment initiation).

- Proportion of individuals retained in care at 6 and 12 months after enrollment in care (i.e., retention in care).

- Proportion of individuals adhering to ART treatment measured by: (1) self-reporting at 6 and 12 months; and (2) viral suppression (through viral load testing) at 6 and 12 months.

The intervention arm comprised four districts where Sauti operates in the Njombe region and the comparison arm comprised three districts where Sauti operates in the Mbeya region. The community-based ART service delivery model was built upon Sauti's existing community-based HIV testing and counseling plus (CBHTC+) intervention that also provided other services to key populations: sexually transmitted infection (STI) screening and periodic presumptive treatment, escorted referrals of HIV-positive clients to HIV treatment facilities, condom promotion and provision, family planning counseling and methods, referrals for cases of gender-based violence, TB screening, and alcohol and drug screening. These services were offered to both arms; the 
community-based ART delivery was added for the intervention arm. In the intervention arm, clinical staff trained in ART provision provided ART services through the CBHTC mobile and homebased platform. The comparison arm participants were referred to government-designated ART care and treatment clinics (CTC).

From July to October 2017, the research team enrolled 617 FSWs (309 in intervention, 308 in comparison) into the study. Eligible FSWs were HIV positive, not on ART (or previously on ART but not for the last three months), aged 18 and older, selling sex for money or goods at least once in the past 6 months, and planning to reside in their respective region for the next 12 months. The recruitment was carried out through Sauti's CBHTC+ services. Behavioral survey data were collected at baseline, 6 months, and 12 months. Viral load was measured at the 6-and 12-month study visit. The questionnaire elicited information on demographics, HIV-related risk behaviors, HIV testing history, health status, sexual violence, self- and external stigma, and enrollment into ART (for those who knew their HIV status for at least a month prior to the survey). The follow-up surveys included the same behavioral questions with additional questions regarding ART uptake, adherence, and experience with HIV treatment services. In-depth interviews were conducted with a subsample of the FSW cohort participants ( 12 from each arm) to assess their perceptions of the ART services received and barriers and facilitators for ART initiation and retention.

\section{KEY FINDINGS}

\section{FSWs in the community-based ART arm were more likely to initiate ART than FSWs in the comparison arm}

ART initiation was significantly higher in the intervention arm compared to the comparison arm at midline (100 percent vs. 72 percent, $p<0.001$ ). In multivariate regression for ART initiation at 12 months, ART initiation was significantly associated with receiving the community-based ART intervention (adjusted odds ratio [AOR]: 19.0, 95 percent confidence interval [Cl]: 4.4-81.6). Those with higher internalized HIV-related stigma were also significantly less likely to have initiated ART at 12 months (AOR: 0.48, 95 percent Cl: 0.23-0.97).

\section{FSWs receiving community-based ART had higher retention rates; retention remained high after 12 months}

Self-reported current antiretroviral (ARV) usage (retention) was significantly higher in the intervention arm compared to the comparison arm at both 6 months (100 percent vs. 96 percent, $p<0.01$ ) and 12 months (99 percent vs. 77 percent, $p<0.001$ ). In multivariate analysis, retention was significantly associated with receiving the community-based ART intervention (AOR: 16.0, 95 percent Cl: 4.6-55.7).

\section{Significant drop off in retention from 6 months to 12 months for comparison group}

Retention in ART was high in both arms at six months (96 percent in the comparison and 100 percent in the intervention arms); however, retention declined significantly to 77 percent in the 
comparison arm (compared to 99 percent in the intervention arm; $\mathrm{p}<0.05$ ). In the intervention arm, adherence also improved over time. Missing ARV pills at least once during the last 30 days declined significantly from 22 percent to 10 percent $(p<0.01)$ in the intervention arm, while in the comparison arm, the observed decrease was smaller, moving from 26 percent to 18 percent $(p<0.05)$. There were no significant changes in viral suppression from 6 to 12 months in either arm.

\section{FSWs reported high levels of internalized HIV stigma; those with higher internalized stigma were less likely to initiate ART}

FSWs in both arms reported fairly high levels of internalized stigma at all time points (approximately 20-75 percent depending on scale items); however, it was higher in the comparison arm for most of the internalized stigma scale items. Moreover, in the adjusted regression analysis, those with higher internalized HIV-related stigma were significantly less likely to have initiated ART (AOR: 0.48, 95 percent $\mathrm{Cl}$ : 0.23-0.97). In other words, those who felt more shame and negative feelings with regard to their HIV diagnosis were significantly less likely to initiate ART.

\section{Adherence was fairly high in both arms; there was no effect of the intervention on adherence}

Approximately 15 percent had missed a dose of ARVs in the past seven days at midline in both arms, and 7 percent (comparison) and 13 percent (intervention) missed a dose at endline $(p=0.039)$. However, multivariate analysis conducted for the 12-month follow-up indicated the intervention did not have an effect on adherence.

\section{Viral suppression was equally high in both arms}

Viral suppression (defined as $<1,000$ copies $/ \mathrm{ml}$ ) among those who initiated ART was fairly high (between 80 and 85 percent) at midline and endline, and there were no differences by arm.

\section{Satisfaction with ART services was higher among FSWs receiving the community-based ART services}

FSWs in in-depth interviews in both arms spoke highly of the ART services they received (at CTCs in the comparison arm and through the community-based ART in the intervention arm) with regard to client-provider interactions, information they received (adherence counseling, risk reduction), and the perceived competence of the providers. Specific aspects of the communitybased ART intervention they found appealing were: greater convenience (of time and place) for ARV delivery, greater confidentiality, reduced travel distance and associated cost, and the benefit of bypassing long waits at the government CTC facilities.

Participants in the intervention arm were significantly more likely to rate themselves after the last ART visit as "very satisfied" compared to the comparison arm at midline (97 percent vs. 59 percent, $p<0.001$ ) and at endline (99 percent vs. 80 percent, $p<0.001)$. 


\section{Reduced sexual risk behaviors in both arms}

There was a significant increase in condom use at last sex with a non-paying partner from baseline to endline in the comparison arm ( 21 percent to 47 percent, $p=0.001$ ) and the intervention arm (28 percent to 36 percent, $p=0.001$ ). Condom use at last sex act with $a$ paying partner also increased significantly in both arms (comparison: 36 percent to 69 percent, $p=0.001$; intervention: 46 percent to 58 percent, $p=0.005$ ).

Disclosure to their steady (non-paying) partner and knowing their steady partner's HIV status also increased significantly in both arms. Despite an increase in disclosure from baseline to endline, experience of violence did not increase over the same time period.

\section{CONCLUSIONS AND RECOMMENDATIONS}

These findings suggest that the community-based ART model can close critical gaps in the HIV care continuum cascade. In particular, community-based ART can improve ART initiation and retention. Adherence and viral suppression in both arms were fairly high. FSWs found the community-based ART model very appealing and there was greater satisfaction with the services. Thus, the following are recommendations based on the findings of this study:

We strongly recommend a community-based approach to ART delivery. In particular, the initial process of enrolling newly diagnosed HIV-positive FSWs immediately through community-based services is critical in ensuring that we do not miss the opportunity to enroll these individuals. We also recommend strategies (e.g., peer support groups, educating oneself/others about HIV, viewing HIV as a manageable condition, and facilitated HIV disclosure) be an integral part of the HIV services they receive. Counseling addressing internalized stigma can help patients with their self-perceptions in relation to their HIV diagnosis so that they can adopt a healthier self-image and better cope with a positive HIV diagnosis. 


\section{INTRODUCTION}

Tanzania has a mature, generalized HIV epidemic with an HIV prevalence of 4.9 percent among the adult population (Government of Tanzania, Tanzania HIV Impact Sur Tanzania Commission for AIDS [TACAIDS], and Zanzibar AIDS Commission [ZAC] 2017). Although the epidemic is generalized, female sex workers (FSWs) bear a disproportionately high HIV prevalence (26.6 percent) compared to the HIV prevalence among the general population of adult women (6.5 percent) (Ministry of Health and Social Welfare, National AIDS Control Programme 2014, TACAIDS et al. 2013; Somi et al. 2012). The Iringa region (which includes the newly established Njombe region) has the highest HIV prevalence among FSWs (32.9 percent) (Ministry of Health and Social Welfare, National AIDS Control Programme 2014).

According to the 2016 Tanzania HIV Impact Survey, it was estimated that 52 percent of people living with HIV aged 15 to 64 years knew their HIV-positive status (56 percent of HIV-positive females and 45 percent of HIV-positive males), and of those 91 percent (93 percent of females and 86 percent of males) self-reported currently using antiretroviral treatment (ART) (Government of Tanzania, TACAIDS, and ZAC 2017). Of those who self-reported current ART use, an estimated 88 percent (89 percent of females and 84 percent of males) were virally suppressed. Despite this progress towards achieving 90-90-90 targets, in Tanzania, like many countries in the region, the HIV care and treatment program is characterized by late and low enrollment and retention in care and treatment services (Somi et al. 2012). Data on these indicators among FSWs in Tanzania are limited; however, they are likely lower than among the general population. A recent study among community-recruited FSWs in Tanzania indicated that 31 percent were previously aware of their HIV status, out of which 69 percent were on ART and, of those on ART, 70 percent were virally suppressed (Nakanwagi et al. 2016).

Sex workers face greater challenges than the general population in accessing HIV care and treatment services once diagnosed with HIV. Barriers for initiating, being retained in, and adhering to ART include the inability to attend regular medical appointments, difficulty reaching distant clinics, out-of-pocket costs associated with care, lack of knowledge and misperceptions of treatment, fear of being known as an FSW and/or HIV-positive, providers' stigmatizing attitudes, and negative experiences dealing with the health care system (Mountain et al. 2014; Lancaster et al. 2016; Nakanwagi et al. 2016; Scorgie et al. 2013). FSWs in Iringa and Njombe regions also reported significant barriers in accessing general population services, including being denied HIV testing services, providers' lack of knowledge and sensitivity to meet FSWs' needs, and HIVrelated stigma and discrimination (Research to Prevention [R2P] 2013).

The government of Tanzania began to roll out a "test and start" approach in October 2016. This approach recommends ART initiation to all individuals living with HIV regardless of World Health Organization (WHO) clinical stage or CD4 cell count (Ministry of Health and Social Welfare and National AIDS Control Programme [NACP] 2014b). The prescription of ART is done through trained health care providers and pharmacists at designated health facilities. The guidelines also emphasize integration of services, by providing antiretrovirals (ARVs) at other clinics such as maternal and child health and TB clinics. Key and hard-to-reach populations living with HIV, 
including FSWs, are referred to the mainstream services. Efforts are being made to improve linkages and retention for FSWs, including escort services from HIV testing and counseling (HTC) sites to government ART care and treatment centers (CTCs), provider-initiated counseling, and stigma reduction among ART clinic staff.

There is growing evidence that community-led and community-based approaches are critical for programming for key populations at high risk for HIV such as female sex workers. These approaches with strong community involvement can increase linkage to HIV care and initiation and retention of ART, as well as reduce the burden for both patients and facility staff (Bememlmans et al. 2014; Sharma et al. 2015; Suthar et al. 2013; Konate et al. 2011). Community models include the use of outreach, mobile services, drop-in centers, peer educators/ navigators, community support groups, and community health workers. Several studies from sub-Saharan Africa have shown improved HIV treatment outcomes with the use of community health workers (or peer health workers), including uptake of HIV services, retention in care, and increased dignity and quality of life of people with HIV (Mwai et al. 2013). Additionally, the WHO Consolidated Guidelines for Key Populations recommends service integration (for clients to receive the services they need in one place), decentralization (to offer services closer to where the target populations are), and task shifting approaches based on initial successes observed in other countries, including Kenya, Ghana, India, Nigeria, Thailand, and Uganda (WHO et al. 2013, WHO 2014). In particular, the WHO recommends several solutions to make access to ART easier, more acceptable, and more effective for FSWs. These include: clinical services at sites located near places of sex work, flexible clinic hours (weekends, evenings), emergency drug pick-ups, patient-held records for sex workers who may seek ART at different sites, and non-judgmental staff attitudes.

In the context of a growing need for sustainable programming, for expanding the reach of ART services for FSWs, and the mounting evidence for community-based programming for key populations, we conducted a study to assess the effectiveness of a community-based ART distribution program for HIV-positive FSWs whereby HIV testing, care, and ART services were provided by trained ART providers through community-based HIV testing and counseling mobile and home-based platforms. This project is the first community-based ART service delivery strategy for FSWs using a community-based HIV testing and counseling services (CBHTC) mobile and home-based platform in Tanzania. 


\section{METHODOLOGY}

\section{OBJECTIVES}

The goal of this study was to pilot and evaluate the impact of a community-based model of ART delivery whereby HIV care and ART provision was provided by clinicians at non-mainstream HIV prevention sites, specifically CBHTC. The study aimed to assess the effectiveness of the intervention on the following primary outcomes:

- Proportion of individuals who are linked to care and initiate ART treatment (i.e., treatment initiation).

- Proportion of individuals retained in care at 6 and 12 months after enrollment in care (i.e., retention in care).

- Proportion of individuals adhering to ART treatment measured by: (1) self-reporting at 6 and 12 months; and (2) viral suppression (through viral load testing) at 6 and 12 months.

- Estimated annual ART-related service cost per ART client in the community-based intervention group (all costs needed to deliver ART service to a patient).

\section{STUDY DESIGN}

A quasi-experimental prospective cohort study was conducted to examine differences in treatment outcomes between the intervention and comparison arms. The study entailed a baseline behavioral survey, and 6- and 12-month follow-up study visits (behavioral survey and viral load testing).

\section{Study sites}

The study was conducted in Njombe (intervention) and Mbeya (comparison) regions in Tanzania. These two regions are part of the Sauti Project-a large USAID-funded HIV prevention program for key populations led by Jhpiego, the implementing partner of this research project. Njombe was purposely selected because of its high HIV burden-33 percent among FSWs in Iringa, of which Njombe was part until 2012 (Ministry of Health and Social Welfare and NACP 2014b), high estimated number of FSWs $(3,871$ ) (Ministry of Health and Social Welfare and NACP 2014a), and its designation as a priority region by the donor. Mbeya region was selected as the comparison site, as Sauti was similarly operating its CBHTC mobile and home-based platforms in the region and it had a comparably high HIV prevalence of 29 percent among FSWs (Ministry of Health and Social Welfare and NACP 2014b), and a high number of FSWs $(10,152)$ (Ministry of Health and Social Welfare and NACP 2014a). 


\section{Description of intervention}

Table 1 details the services provided in the intervention and comparison arms.

Table 1 Services provided in the intervention and comparison arms

\begin{tabular}{|c|c|c|}
\hline & Intervention arm (Njombe) & Comparison arm (Mbeya) \\
\hline \multirow[t]{3}{*}{ Testing } & When: Daily/moonlight, walk-ins & When: Daily/moonlight, walk-ins \\
\hline & $\begin{array}{l}\text { Where: Community locations-mobile } \\
\text { tents, rented rooms, or FSW's home. } \\
\text { Service provided close to community; } \\
\text { easy to access, less crowded, flexible } \\
\text { time/days. }\end{array}$ & $\begin{array}{l}\text { Where: Community locations-mobile } \\
\text { tents, rented rooms, or FSW's home. } \\
\text { Service provided at limited number of } \\
\text { static CTC facilities. Longer commuting, } \\
\text { and often more crowded, fixed working } \\
\text { hours/days. }\end{array}$ \\
\hline & $\begin{array}{l}\text { Provider: Nurses \& clinicians, peer } \\
\text { educator mobilization }\end{array}$ & $\begin{array}{l}\text { Provider: Nurses \& clinicians, peer } \\
\text { educator mobilization }\end{array}$ \\
\hline \multirow[t]{3}{*}{$\begin{array}{l}\text { Linkage to } \\
\text { care }\end{array}$} & $\begin{array}{l}\text { When: Same day ART and received one } \\
\text { month of ARV drug supply }\end{array}$ & When: Referral to government facilities \\
\hline & $\begin{array}{l}\text { Where: Community locations-mobile } \\
\text { tents, rented rooms }\end{array}$ & Where: Government facilities \\
\hline & Provider: Nurses \& clinicians & Provider: Doctor \\
\hline \multirow{3}{*}{$\begin{array}{l}\text { Refill \& } \\
\text { routine } \\
\text { clinical exam }\end{array}$} & $\begin{array}{l}\text { When: M0, M1, M3, thereafter every } 4 \\
\text { months }\end{array}$ & \\
\hline & $\begin{array}{l}\text { Where: Community locations-mobile } \\
\text { tents, rented rooms, homes }\end{array}$ & Provider: Doctor \\
\hline & Provider: Nurses \& clinicians & \\
\hline Follow-up & $\begin{array}{l}\text { Peer educators stayed in regular contact } \\
\text { with participants through text messaging } \\
\text { and WhatsApp messaging and met them } \\
\text { monthly to assess their adherence and } \\
\text { side effects, and provide peer support. }\end{array}$ & $\begin{array}{l}\text { No follow-up contact in between CTC } \\
\text { visits. }\end{array}$ \\
\hline
\end{tabular}

Based on existing evidence and in consultation with in-country partners, including Sauti (the largest program that provides HIV prevention services to key populations in Tanzania), National AIDS Control Program, Njombe Regional Health Medical Team, USAID Washington, and USAID Tanzania, we developed an intervention package for the study (Table 1). The intervention aligned closely with the national guidelines on management of HIV and the community-based HIV and AIDS services guidelines that were in development at the time.

The intervention was built upon Sauti's existing Community-based HIV Testing and Counseling Plus (CBHTC+) service delivery platform, which provides HTC, STI screening and periodic presumptive treatment, escorted referrals of HIV-positive clients to HIV treatment facilities, 
condom promotion and provision, family planning counseling and methods, referrals for cases of gender-based violence, TB screening, and alcohol and drug screening. The CBHTC+ teams move around the region to make sure that services are close to those in need, removing one of the barriers to health care access: distance and transportation costs. Sites for CBHTC+ were often chosen based on several factors, including the potential size of the target populations at the site (hotspots), the ability to have enough private rooms for different activities, and the safety of the target populations. CBHTC+ focuses on serving key populations at higher risk of HIV infection, including FSWs, men who have sex with men, and vulnerable adolescent girls. However, its services were also available to the general population.

In Njombe, the community-based ART services were added for the intervention. Specifically, clinical staff were recruited to form the community-based health services team to provide the ART services through the $\mathrm{CBHTC}+$ mobile and home-based platform. As required by the government, HIV-positive clients were required to register for ART at the government CTC site and must have a CTC number. For the purpose of this study, all CBHTC+ "sites" were considered "satellite" facilities and affiliated to a government-managed CTC in order to obtain a CTC number and ensure ARV supply. The team was trained on recruitment of eligible candidates to the study, assessing clients' readiness for ART initiation, ART delivery, ART adherence counseling, and protocol for when clients should be referred to facility-based ART services (e.g., complications, opportunistic infections, or pregnancy). Each team comprised one clinician and two nurses both trained in HTC and ART services, and at least three peer educators.

\section{Distribution of ARV drugs to CBHTC+ services}

Although clients registered for ART through the $\mathrm{CBHTC}+$, as required by the government, they were affiliated with a CTC site and were given a CTC number (i.e., registered under that CTC officially). This allowed for the ARVs to be available to the CBHTC+ team to deliver to the patients free of charge from their "mother" CTC facility.

At enrollment, FSWs in the intervention arm received a one-month ARV drug supply. At the end of that month, at the second appointment, they received a two-month supply. At the end of the third month, they received a three-month supply.

To monitor the consistency and quality of service delivery throughout the study, trained quality assurance staff observed clinical and non-clinical service aspects according to existing quality standards and measurement tools developed by the study team and NACP.

Individuals who tested HIV positive through the CBHTC+ site in the intervention region who did not wish to participate in the study were referred to appropriate designated CTC facilities.

\section{Comparison arm}

Participants in the comparison arm were referred to the government CTCs for current standardof-care ART services, which entailed test and start per the national guidelines. Patients returned for monthly visits for the first six months for evaluation and drug refills as well as adherence counseling. The main difference between the two arms is that the comparison arm did not provide any community-based ART services. 
We listed ART facilities in the three comparison districts, and clients could select a government CTC where they wished to go. A Sauti outreach team was available to counsel and discuss facility options as well as provide escort services to the chosen CTC if clients desired. Clients were encouraged to disclose to health providers that they were sex workers so that they could qualify for initiating ART immediately. To facilitate disclosure, FSWs were counseled on the benefits of initiating ART early and that they qualified to start ART immediately.

\section{DATA COLLECTION METHODS}

\section{Study population and recruitment}

Study participants were actively recruited from July to October 2017. The study was advertised through brochures, announcements during peer-education outreach activities, announcements at targeted health facilities in the catchment area, drop-in centers, CBHTC+ sites, peer support meetings, and HIV counseling sessions. For recruitment, HIV testing was performed to identify and confirm HIV seropositive individuals through Sauti's CBHTC+ services. Individuals tested included those who were testing for the first time as well as those who already knew they were HIV seropositive but were interested in enrolling in the study. Testing followed the government guidelines (serial tests). If found to be HIV positive, eligibility criteria were assessed, and those who met the eligibility criteria were asked to participate in the study.

Participants were enrolled if they were female, 18 years of age or older, reported a history of selling sex for money at least once in the past six months, were HIV positive and not on ART (e.g., newly diagnosed HIV positive not on ART, previously diagnosed but not in care, in care but not on ART, or previously on ART but discontinued for at least three months) as identified through community-based testing sites, agreed to reside within the study catchment area for the next 12 months, and were willing to provide informed consent.

If eligible and enrolled in the cohort study, participants in the intervention arm were registered into HIV care through the CBHTC+ services right away if they chose to initiate ART. Participants who were not ready for ART were given a referral slip to go to a CTC facility or return to receive ART through the CBHTC+. Participants in the comparison arm were given a referral card with a list of available government-designated CTC facilities. Escort services were provided if clients in the control arm desired.

We estimated a sample size for the study to detect a difference of 20 percentage points with 80 percent power in the key outcomes of ART initiation, ART retention, and viral suppression between the two arms at 12 months post-intervention at the $p<0.05$ level and accounting for design effect of 1.5 and loss to follow-up (LTFU) of 20 percent. Based on Sauti's routine programming data, we anticipated that 90 percent of the study participants in the intervention and 70 percent in the comparison arm would be initiated, 90 percent and 70 percent of those who initiated would be retained in care, and 80 percent and 60 percent of initiates would achieve viral suppression, respectively. The final sample size was determined as 300 per arm for the outcome of viral suppression, and 193 per arm for the outcome of initiation and retention. 


\section{Data collection}

\section{Baseline data collection}

Cohort participants completed a face-to-face interview. The structured questionnaire collected information on demographics, health status, sexual behaviors, sexual violence, HIV testing history, external and internal stigma, and STI diagnoses. Baseline viral load was not measured since it was not part of the clinical care or National Guidelines and the goal was to assess viral suppression as opposed to change in viral load. All interviews were electronically data captured using computer-assisted personal interviewing. Contact information for all participants in the cohort study was recorded in a password-protected registry for follow-up interviews at 6 and 12 months. Interviews took place in private venues such as the participant's or a peer educator's home or rented room in a guesthouse. Participants received 10,000 Tanzanian shillings (about US\$ 4.50) at each study visit.

\section{Follow-up data collection and 6 and 12 months}

All cohort participants were invited for a follow-up study visit at 6 and 12 months after their baseline study visit. Follow-up interviews were conducted at pre-determined sites independent from their ART follow-up visits with the CBHTC+ team or any follow-up visits to the CTC. The follow-up interviews took place in similar places as the baseline study interviews. The interview elicited similar information as the baseline interview; additional questions related to ART uptake, adherence, and experience/exposure with HIV treatment services were included in the follow-up questionnaire. Additionally, participants in both arms underwent viral load testing using dried blood spot sample (DBS) at the 6- and 12-month study visits.

\section{Qualitative data collection}

Semi-structured in-depth interviews (IDIs) were conducted with FSWs in both arms, and with clinical and non-clinical staff of the community-based ART intervention (intervention arm) or of the CTCs (in the comparison arm) at 12 months for the purpose of understanding success and lessons learned from the intervention strategy. We selected a small number of FSW participants from among the cohort participants (12 from each arm). Although we tried to diversify by treatment status (current ART usage or not), most ended up being those who were on treatment since the majority of participants were currently on ART at 12 months, particularly in the intervention arm. The interviews asked a series of open-ended questions that explored their perspectives on ART initiation, facilitators and barriers to accessing care, and experiences with the services they received.

A total of 12 (intervention) and 8 (comparison) service providers were interviewed with openended questions at 12 months. The interviews assessed their perception of community-based ART (for those in the intervention arm) and of ART services generally for FSWs. Providers interviewed included ART doctors and nurses, CTC coordinators, CTC providers, lab technicians, and the Regional AIDS Control Coordinator of the two regions. 


\section{DBS sample collection and testing}

DBS samples were collected from participants and then transported in a dry condition at ambient temperature to the testing laboratory at Ifakara Health Institute Laboratories in Ifakara, Tanzania. Testing was carried out following the instructions from the assay manufacturer.

HIV-1 loads were quantified using The Abbott RealTime HIV-1 assay (Abbott Molecular Inc., Des Plaines, IL, USA). The Abbott m2000sp is an automated sample preparation unit which extracts HIV-1 RNA, and the Abbott m2000rt is an amplification and detection unit. Quantification limits are between 40 copies $/ \mathrm{ml}$ and 10,000,000copies $/ \mathrm{ml}$. Results for samples with values below 40 copies/ml were termed as "not detected," and none of the samples had a value higher than upper quantitation limit.

\section{Cost data collection}

Using a micro-costing approach, we retrospectively measured quarterly quantities and prices of essential input categories to deliver ART service to patients: personnel; ARV drugs; transport costs; other drugs and HIV tests (cotrimoxazole, viral load, and CD4); and office, utilities, and external costs. These costs were valued at market prices, regardless of whether they were donated, adopting an economic rather than a financial approach. Total annual costs of the intervention were calculated as the sum of the costs of the aforementioned categories. Recurrent supplies' costs such as ARV drugs, other drugs, and tests were calculated as the total sum of supplies multiplied by their price. Transport costs included rent costs and per diems. Office costs, utilities, and other external costs were prorated according to the proportion of cost used specifically in the intervention.

\section{Ethical review}

Ethical approval was obtained from Tanzania's National Health Research Ethics Committee (NatHREC), National Institute for Medical Research (NIMR), the Mbeya Zonal Consultant Hospital, Mbeya Research and Ethics Committee (Tanzania), and the Population Council Institutional Review Board (USA). Informed written consent was obtained from all participants in Swahili.

\section{Data analysis}

Data were analyzed in Stata analysis software (Version 14.1, College Station, Texas). Descriptive analysis was conducted comparing baseline characteristics of the two arms, comparing lost to follow-up participants to those retained in the study, and comparing treatment-related outcomes (e.g., self-reported ART initiation, currently on ART, missing dose in past 7 days, stopped taking ART for $>30$ days continuously) in the two arms. We used Chi-square for categorical variables and T-tests for continuous variables when comparing outcomes across two arms at a single time point and used McNemar test (dichotomous variables) and Paired-T test (continuous variables) for repeated measures (i.e., comparing outcomes of the same individual across two time points). Key outcome measures are defined in Table 2.

Multivariate analysis was performed for four key outcomes at 6 months and 12 months to examine whether participation in the community-based ART intervention was associated with ART 


\begin{tabular}{|c|c|}
\hline Outcome & Definition \\
\hline \multicolumn{2}{|l|}{ Primary outcomes } \\
\hline ART initiation & $\begin{array}{l}\text { Self-report of having been prescribed ARVs by a provider and started } \\
\text { taking them }\end{array}$ \\
\hline Retention & Self-report of current use of ART \\
\hline Adherence & $\begin{array}{l}\text { Self-reported missed dose of ARV in the past } 7 \text { days } \\
\text { Self-reported discontinuation of ARVs for more than } 30 \text { days } \\
\text { continuously }\end{array}$ \\
\hline Viral suppression & Under 1,000 copies/ ml blood ${ }^{a}$ \\
\hline \multicolumn{2}{|l|}{ Other measures } \\
\hline Internalized HIV stigma & $\begin{array}{l}\text { Measured using a validated 6-item scale assessing participants' } \\
\text { feelings of shame and guilt because of living with HIV (Kalichman et al. } \\
\text { 2009) }\end{array}$ \\
\hline
\end{tabular}

${ }^{a}$ WHO Consolidated Guidelines on the Use of Antiretroviral Drugs for Treating and Preventing HIV Infection: Recommendations for a Public Health Approach, Second Edition (2016).

initiation, retention, and adherence at the follow-ups. The selection of independent variables was initially determined through literature, theoretical concepts, and their levels of significance during bivariate analysis. We included key sociodemographic characteristics (age, education, marital status, and mobility) as covariates. As stigma and HIV disclosure is a critical barrier to accessing care and adherence, we also explored how it affects treatment outcomes. Variables significant at $p \leq 0.15$ in bivariate analysis were included in the final multivariate analysis. Unadjusted and adjusted odds ratios and 95 percent confidence intervals are reported. 


\section{KEY FINDINGS}

\section{PARTICIPANT RECRUITMENT AND FOLLOW-UP}

A total of 332 (comparison) and 342 (intervention) FSWs were screened for the study, and 24 and 33 were found ineligible, respectively. Reasons for ineligibility included not selling sex in the past six months, being younger than 18 , being pregnant, and currently taking ART or stopped less than three months ago. Of those found to be eligible, all agreed to participate.

A total of 253 (82 percent) in the comparison and 256 (83 percent) in the intervention arm returned for the 6-month (midline) study visit. For the 12-month visit (endline), a total of 262 (85 percent) in the comparison arm and 265 (86 percent) in the intervention arm returned for the study visit (Figure 1).

We examined differences in loss to follow-up (LTFU) at midline and endline. The table is included in Appendix 1. There were differences in certain characteristics between FSWs who remained in the study and those who were LTFU. At midline, comparison of those who remained in the study and participants LTFU were different by arm. There were no significant differences between the participants LTFU and those who remained in the intervention arm. However, in the comparison arm, those LTFU were slightly younger and less likely to have traveled outside of the region for sex work in the past six months. At endline, there were no significant differences between the participants LTFU and those who remained in the intervention arm. However, in the comparison arm, the only significant difference between the LTFU and those who remained in the comparison arm was age; those who were LTFU were slightly younger.

\section{Characteristics of the participants at baseline}

A total of 617 participants (308 into the comparison and 309 into the intervention) were recruited into the study at baseline (Table 3). Participants in the intervention arm were significantly younger ( 29 years vs. 32 years), had completed more years of education (20 percent vs. 7 percent completed secondary education or more), were more likely to have 51-100 percent of their income from sex work (39 percent versus 24 percent), had more than one non-paying partner in the past month (32 percent versus 12 percent), had traveled out of the region to sell sex in the last six months (36 percent versus 10 percent), and reported experience of sexual violence in the last six months (38 percent versus 5 percent). The two groups were similar with regards to marital status and number of living children.

Those in the intervention group were more likely to have been diagnosed with HIV for longer (as opposed to the day of study enrollment). Baseline data indicate gaps in HIV service uptake in both arms. Among a sub-sample who had known their status for more than a month before the study $(n=97 / 617)$, only 59 percent had registered in HIV care (72 percent in the intervention and 50 percent in the comparison). The main reason for not registering in care was that they felt healthy 
Figure 1 Participant enrollment and follow-up

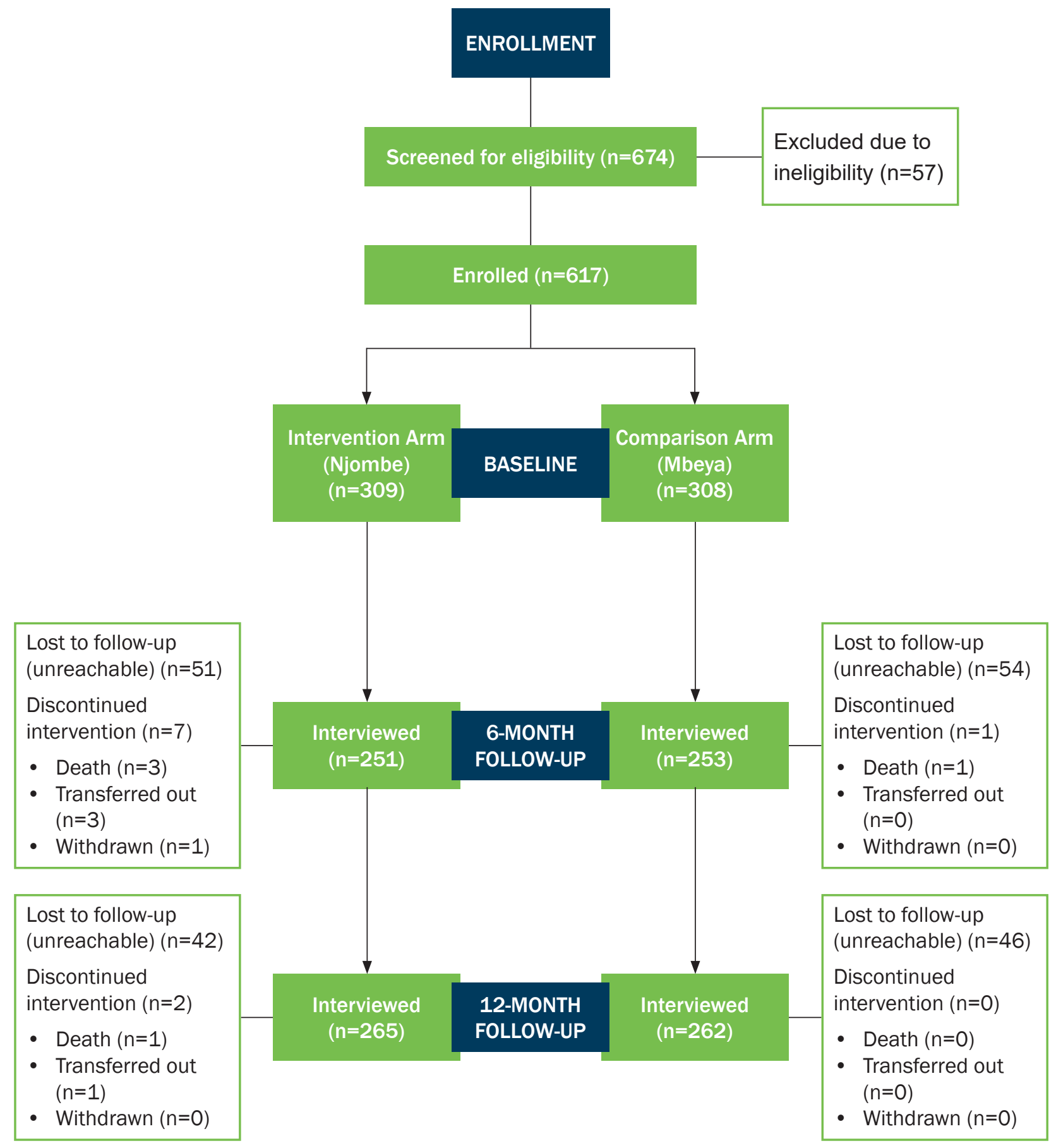


Table 3 Characteristics of the study population in the intervention $(n=309)$ and comparison $(n=308)$ arms at baseline

\begin{tabular}{|c|c|c|c|}
\hline Variable & $\begin{array}{c}\text { Comparison } \\
(\mathrm{n}=308) \\
\mathrm{n}(\%)\end{array}$ & $\begin{array}{c}\text { Intervention } \\
(\mathrm{n}=309) \\
\mathrm{n}(\%)\end{array}$ & $\begin{array}{c}\text { Total } \\
(\mathrm{N}=617) \\
\mathrm{n}(\%)\end{array}$ \\
\hline Median age (IQR)*** & $32(26-39)$ & $29(25-35)$ & $30(25-37)$ \\
\hline $\begin{array}{l}\text { Education***} \\
\qquad \begin{array}{l}\text { None } \\
\text { Some primary } \\
\text { Secondary or more }\end{array}\end{array}$ & $\begin{array}{c}42(13.6) \\
244(79.2) \\
22(7.2)\end{array}$ & $\begin{array}{c}23(7.4) \\
223(72.2) \\
63(20.4)\end{array}$ & $\begin{array}{l}65(10.5) \\
467(75.7) \\
85(13.8)\end{array}$ \\
\hline $\begin{array}{l}\text { Marital status } \\
\text { Never married } \\
\text { Married, living with a husband } \\
\text { Divorced/widowed/separated }\end{array}$ & $\begin{array}{l}163(52.9) \\
35(11.4) \\
110(35.7)\end{array}$ & $\begin{aligned} 185 & (59.9) \\
22 & (7.1) \\
102 & (33.0)\end{aligned}$ & $\begin{array}{l}348(56.4) \\
57(9.2) \\
212(34.4)\end{array}$ \\
\hline $\begin{array}{l}\text { Number of living children } \\
\text { None } \\
\text { One } \\
\text { More than one }\end{array}$ & $\begin{array}{c}51(16.6) \\
75(24.4) \\
182(59.0)\end{array}$ & $\begin{array}{c}55(17.8) \\
115(37.2) \\
139(45.0)\end{array}$ & $\begin{array}{l}106(17.2) \\
190(30.8) \\
321(52.0)\end{array}$ \\
\hline $\begin{array}{l}\text { Percentage of income from sex work } \\
\text { (past } 6 \text { months)*** } \\
\text { Under } 25 \% \\
26-50 \% \\
51-100 \%\end{array}$ & $\begin{array}{c}72(23.4) \\
163(52.9) \\
73(23.7)\end{array}$ & $\begin{array}{c}80(25.9) \\
110(35.6) \\
119(38.5)\end{array}$ & $\begin{array}{l}152(24.6) \\
273(44.3) \\
192(31.1)\end{array}$ \\
\hline $\begin{array}{l}\text { Number of non-paying sex partners } \\
\text { (past month)***} \\
\text { None } \\
\text { One } \\
\text { More than one }\end{array}$ & $\begin{array}{c}173(56.2) \\
99(32.1) \\
36(11.7)\end{array}$ & $\begin{array}{l}89(28.8) \\
120(38.8) \\
100(32.4)\end{array}$ & $\begin{array}{l}262(42.5) \\
219(35.5) \\
136(22.0)\end{array}$ \\
\hline $\begin{array}{l}\text { Traveled out of the region to sell sex } \\
\text { (past } 6 \text { months)***} \\
\text { No } \\
\text { Yes }\end{array}$ & $\begin{array}{c}276(89.6) \\
32(10.4)\end{array}$ & $\begin{array}{l}199(64.4) \\
110(35.6)\end{array}$ & $\begin{array}{l}475(77.0) \\
142(23.0)\end{array}$ \\
\hline $\begin{array}{l}\text { Experienced sexual violence (at least } \\
\text { once, past } 6 \text { months)*** } \\
\text { Yes } \\
\text { No }\end{array}$ & $\begin{array}{c}1.6(5.0) \\
98.4(303)\end{array}$ & $\begin{array}{l}118(38.2) \\
191(61.8)\end{array}$ & $\begin{array}{l}123(19.9) \\
494(80.1)\end{array}$ \\
\hline $\begin{array}{l}\text { Time since HIV diagnosis*** } \\
\text { Newly diagnosed today } \\
\text { Diagnosed within a month } \\
\text { Diagnosed more than a month ago }\end{array}$ & $\begin{array}{c}138(44.8) \\
112(36.4) \\
58(18.8)\end{array}$ & $\begin{array}{c}56(18.1) \\
214(69.3) \\
39(12.6)\end{array}$ & $\begin{array}{c}194(31.5) \\
326(52.8) \\
97(15.7)\end{array}$ \\
\hline Registered in HIV care $(n=97) * a$ & $29(50.0)$ & $28(71.8)$ & $57(58.8)$ \\
\hline
\end{tabular}

$*: p \leq 0.05 ; * *: p \leq 0.01 ; * * *: p \leq 0.001 ;$ IQR: Interquartile range

${ }^{a}$ Registration in HIV care were asked of those who have known their HIV-positive status for at least a month. 
(53 percent) followed by not wanting others to know about their HIV status (anticipated stigma) (27 percent) (more than one response possible) (Figure 2).

Figure 2 Reasons for not registering in HIV care among FSWs who were diagnosed more than a month ago at baseline (in intervention and comparison groups combined) $(n=40)$

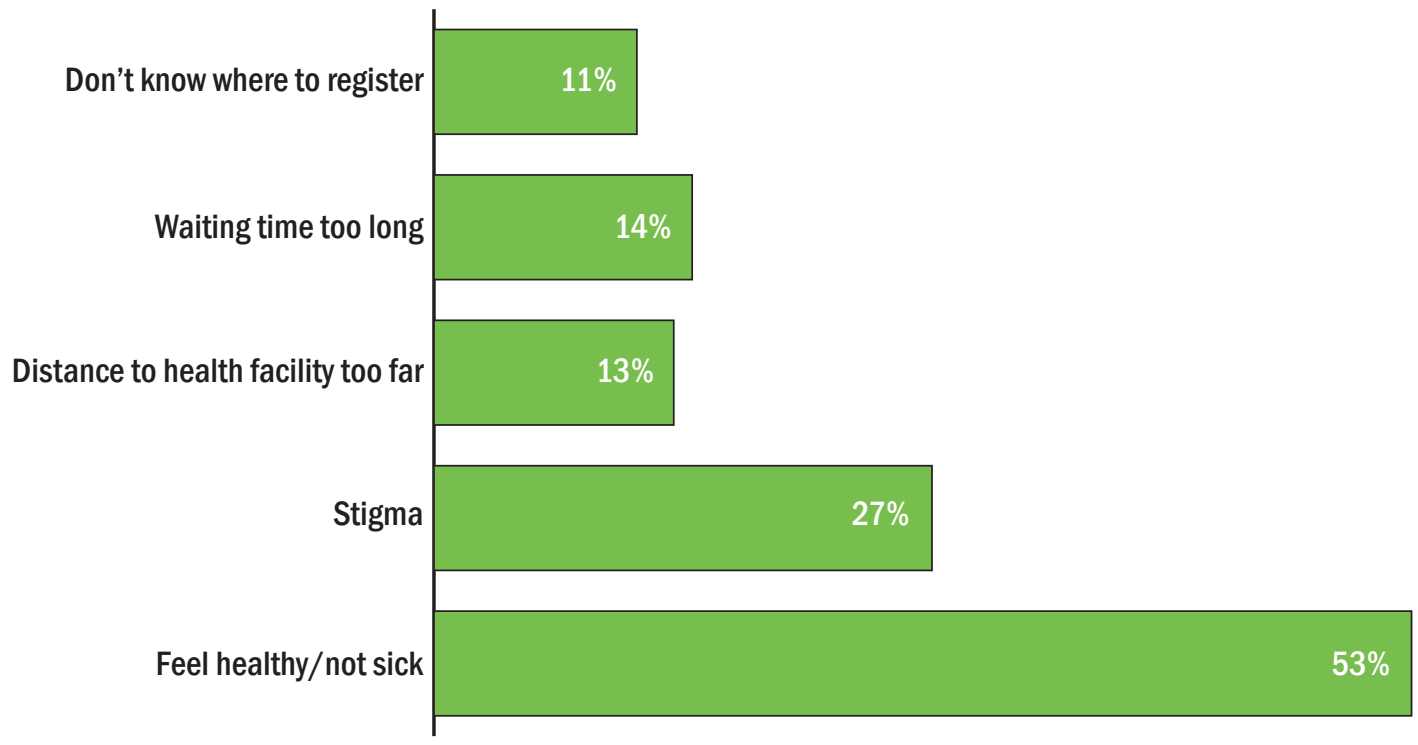

\section{EFFECTIVENESS OF THE INTERVENTION ON IMPROVING HIV TREATMENT OUTCOMES}

Table 4 compares treatment-related outcomes between the two arms at midline and endline and Table 5 shows the results of the bivariate and multivariable analyses for the primary treatment outcomes of ART initiation, retention, and viral suppression at endline (12 months).

\section{ART initiation}

ART initiation was significantly higher in the intervention arm compared to the comparison arm at midline (100 percent versus 72 percent, $p<0.001)$ and at endline (99 percent versus 87, $p<0.001$ ). In multivariate regression for ART initiation at 12 months, ART initiation was significantly associated with receiving the community-based ART intervention (AOR: 19.0, 95 percent Cl: 4.4-81.6). Those with higher internalized HIV-related stigma were also significantly less likely to have initiated ART at 12 months (AOR: 0.48, 95 percent $\mathrm{Cl}$ 0.23-0.97).

\section{Retention in ART}

Retention was based on self-report of current usage of ART. Retention was significantly higher in the intervention arm compared to the comparison arm at midline (100 percent vs. 95 percent, $p<0.01$ ) and at endline (99 percent versus 77 percent). In multivariate analysis, 12-month retention was significantly associated with receiving the community-based ART intervention (AOR: 16.0, 95 percent $\mathrm{Cl}: 4.6-55.7)$ and age older than 30 years (AOR: 2.1, 95 percent $\mathrm{Cl}$ : 1.01-4.5). 
Table 4 Comparisons of ART outcomes at midline and endline by study arm

\begin{tabular}{|c|c|c|c|c|c|c|}
\hline & $\begin{array}{c}\text { Comparison } \\
\begin{array}{c}\mathrm{N}=253 \\
\%\end{array}\end{array}$ & $\begin{array}{l}\text { Midline } \\
\text { Intervention } \\
\begin{array}{c}\mathrm{N}=256 \\
\%\end{array}\end{array}$ & p-value & $\begin{array}{c}\text { Comparison } \\
\begin{array}{c}\mathrm{N}=262 \\
\%\end{array}\end{array}$ & $\begin{array}{l}\text { Endline } \\
\begin{array}{l}\text { Intervention } \\
\qquad \begin{array}{c}\mathrm{N}=265 \\
\%\end{array}\end{array}\end{array}$ & p-value \\
\hline $\begin{array}{l}\text { Initiated ART } \\
\text { (being prescribed } \\
\text { the pill since } \\
\text { joining the study) }\end{array}$ & $\begin{array}{c}72.4 \\
(181 / 250)\end{array}$ & $\begin{array}{c}100.0 \\
(256 / 256)\end{array}$ & $<0.001$ & $\begin{array}{c}86.8 \\
(224 / 258)\end{array}$ & $\begin{array}{c}99.3 \\
(263 / 265)\end{array}$ & $<0.001$ \\
\hline $\begin{array}{l}\text { Retained in ART } \\
\text { (denominator } \\
\text { included all } \\
\text { participants } \\
\text { who were re- } \\
\text { interviewed) }\end{array}$ & $\begin{array}{c}95.0 \\
(171 / 180)\end{array}$ & $\begin{array}{c}100.0 \\
(254 / 254)\end{array}$ & $<0.01$ & $\begin{array}{c}77.1 \\
(199 / 258)\end{array}$ & $\begin{array}{c}98.9 \\
(262 / 265)\end{array}$ & $<0.001$ \\
\hline $\begin{array}{l}\text { Missed ARV pills } \\
\text { at least one day } \\
\text { during the past } 7 \\
\text { days }\end{array}$ & $\begin{array}{c}16.4 \\
(25 / 152)\end{array}$ & $\begin{array}{c}17.2 \\
(37 / 214)\end{array}$ & 0.83 & $\begin{array}{c}7.0 \\
(14 / 199)\end{array}$ & $\begin{array}{c}13.0 \\
(34 / 262)\end{array}$ & 0.039 \\
\hline $\begin{array}{l}\text { Missed ARV pills } \\
\text { at least one day } \\
\text { during the past } \\
30 \text { days }\end{array}$ & $\begin{array}{c}22.0 \\
(35 / 159)\end{array}$ & $\begin{array}{c}25.7 \\
(55 / 214)\end{array}$ & 0.41 & $\begin{array}{c}9.6 \\
(19 / 199)\end{array}$ & $\begin{array}{c}17.9 \\
(47 / 262)\end{array}$ & 0.011 \\
\hline $\begin{array}{l}\text { Stopped taking } \\
\text { medication for } \\
\text { more than } 30 \\
\text { days in the past } 6 \\
\text { months }\end{array}$ & $\begin{array}{c}5.7 \\
(9 / 159)\end{array}$ & $\begin{array}{c}0.9 \\
(2 / 214)\end{array}$ & $<0.008$ & $\begin{array}{c}3.5 \\
(7 / 199)\end{array}$ & $\begin{array}{c}0.4 \\
(1 / 262)\end{array}$ & $<0.001$ \\
\hline $\begin{array}{l}\text { Ran out of all } \\
\text { ARV pills (past } 6 \\
\text { months) }\end{array}$ & $\begin{array}{c}6.9 \\
(11 / 159)\end{array}$ & $\begin{array}{c}6.5 \\
(14 / 200)\end{array}$ & 0.886 & $\begin{array}{c}4.5 \\
(9 / 200)\end{array}$ & $\begin{array}{c}2.6 \\
(7 / 262)\end{array}$ & 0.287 \\
\hline $\begin{array}{l}\text { Shared ARV pills } \\
\text { (past } 6 \text { months) }\end{array}$ & $\begin{array}{c}1.9 \\
(3 / 159)\end{array}$ & $\begin{array}{c}2.3 \\
(5 / 214)\end{array}$ & 0.767 & $\begin{array}{c}4.0 \\
(8 / 199)\end{array}$ & $\begin{array}{c}3.0 \\
(8 / 262)\end{array}$ & 0.574 \\
\hline $\begin{array}{l}\text { Achieved viral } \\
\text { suppression } \\
\text { among those who } \\
\text { initiated }\end{array}$ & $\begin{array}{c}82.0 \\
(200 / 244)\end{array}$ & $\begin{array}{c}79.2 \\
(171 / 216)\end{array}$ & 0.448 & $\begin{array}{c}84.7 \\
(193 / 228)\end{array}$ & $\begin{array}{c}84.1 \\
(174 / 207)\end{array}$ & 0.865 \\
\hline
\end{tabular}

Notes:

Retention in care: Self-reported current use of ART

Viral suppression: Under 1,000 copies/ ml plasma

Total ns do not add up for various variables due to missing data. 


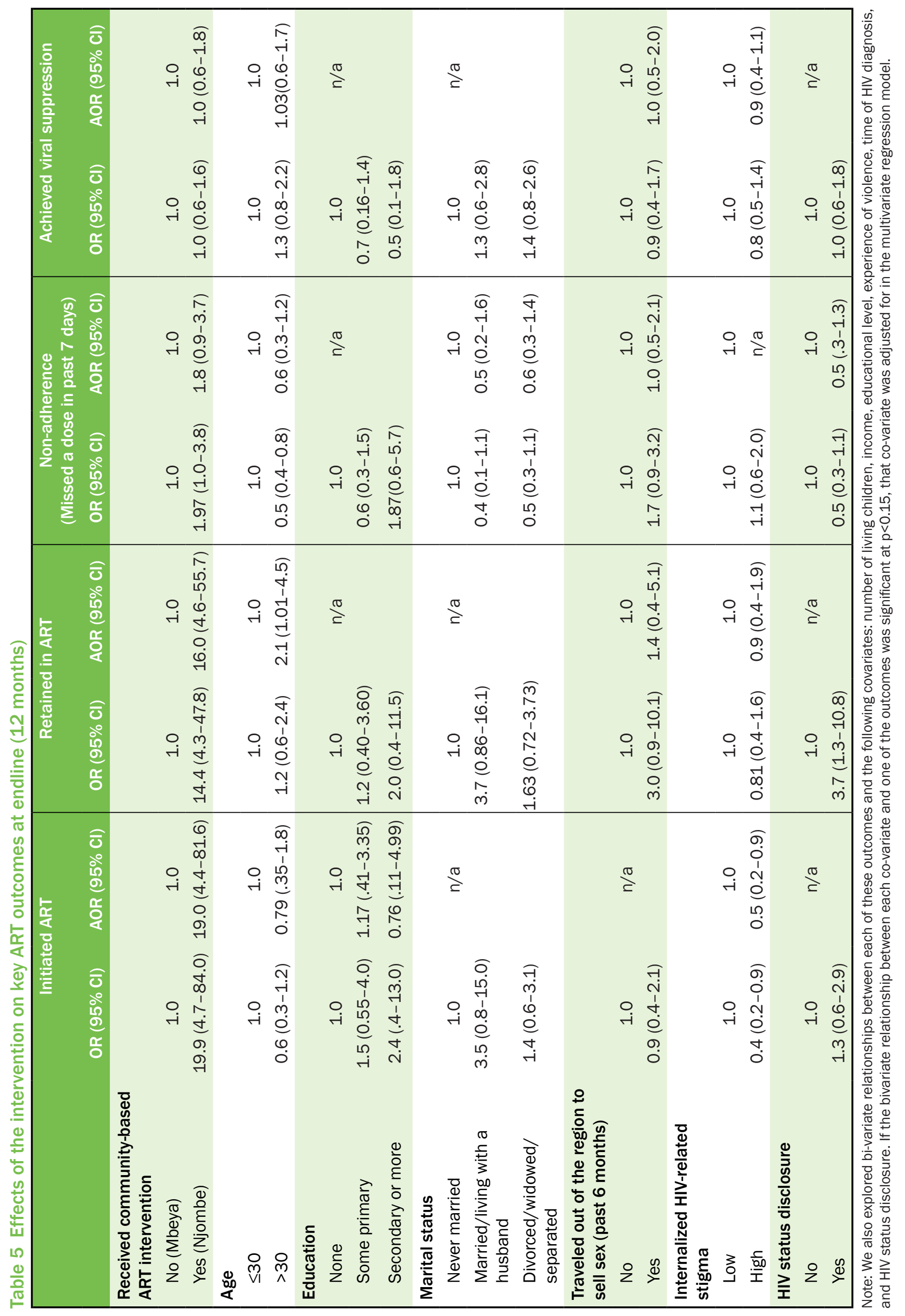




\section{Adherence to ART}

Adherence was based on whether they missed at least an ARV pill in the past 7 and 30 days. At midline, a fairly small proportion (16-17 percent) missed a pill in the past seven days and there was no significant difference between the two arms. However, at endline, a significantly higher proportion missed a pill in the intervention arm compared to the comparison arm (13 percent vs. 7 percent, $p=0.039$ ). For the past 30 days, there were similar findings of no difference between arms at midline but a higher proportion of a missed dose in the intervention arm (18 percent vs. 10 percent, $p=0.011$ ). However, in the multivariable analysis, intervention was no longer associated with 12-month non-adherence.

\section{Discontinuation of ART}

We asked participants on ART whether they stopped taking ARVs for 30 days continuously anytime in the past 6 months. Only a small proportion indicated having stopped at both midline and endline, but a higher proportion indicated doing so in the comparison group compared to the intervention group at midline ( 6 percent versus 1 percent, $p<0.008)$ and at endline $(4$ percent versus 0.4 percent, $p<0.001$ ).

\section{Viral suppression}

A fairly high proportion of those who initiated ART attained viral suppression in both arms at midline (approximately 80 percent) and endline (84 percent). There were no differences between the arms at both time points. In bivariate and multivariate analysis of 12-month viral suppression, viral suppression was not associated with the intervention or any of the selected demographic variables, internalized stigma, or HIV status disclosure.

\section{ART-RELATED SERVICE COST}

The total annual cost to deliver ART services to the entire cohort in the intervention arm was estimated at US\$118,895, which translates to an average annual cost per FSW as US\$ 440. The breakdown of costs from the intervention are shown in Figure 3. Staff costs were US $\$ 60,497$, which represents 50 percent of total annual costs; the cost of ARVs was US $\$ 27,195$, which represents 23 percent of total annual costs; transport costs were slightly lower at US $\$ 24,492$ (21 percent of the total); other drugs and tests accounted for about 6 percent of the total cost; and less than one percent of the total costs were for utilities, office, and external costs.

\section{HIV TREATMENT OUTCOMES: KEY QUALITATIVE FINDINGS}

\section{FSWs found community-based ART delivery appealing}

The qualitative findings from the IDIs with FSWs in both arms support the survey finding that those in the intervention arm were more likely to initiate ART. Participants in the intervention arm indicated that they joined because they found home delivery of ART services appealing. Many reasons were cited for why they preferred home delivery (or delivery to another convenient 


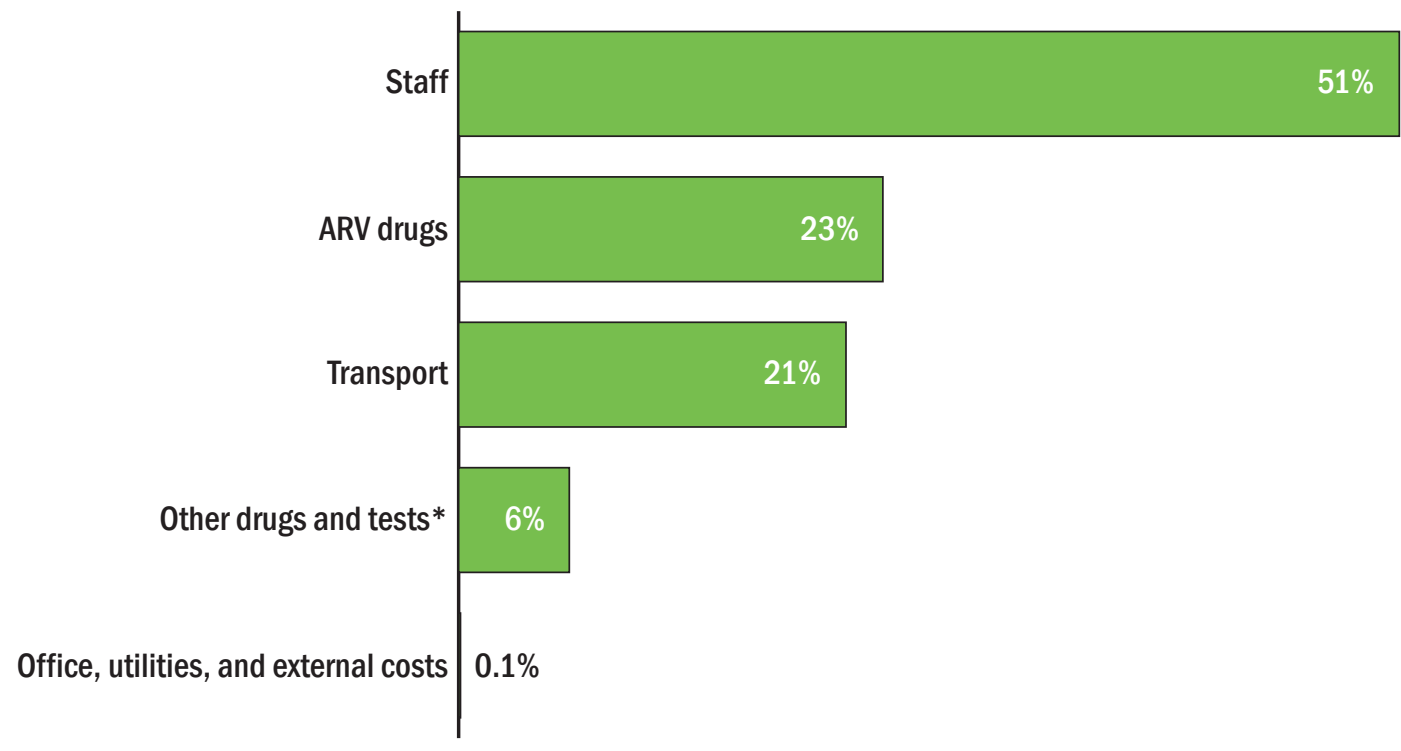

place). For one, it meant that they did not have to travel a long distance to the clinic, thus saving time and money. It was also appealing because it affords greater confidentiality since they would not have to be in a clinic with others. When asked about what motivated them to join the community-based ART program, the following were some of the responses:

I liked this service because it's straightforward, and it is a quick service, one can carry on their jobs while still receiving treatment. And you can get treated when contacting them at any time in case you get sick or an emergency; they can follow you at your convenience location for treatment, so I don't have to attend clinic. Also there is privacy, and no long queues, it's just them and me, and I liked that arrangement.

-Njombe (Intervention)

I was happy with home service. It's usually hard for us to find fare and come for medication; we live far in the villages.

-Njombe (Intervention)

First, they told me that they'd serve us from wherever we are; we'll not be going to congested crowds. I was motivated by that knowing it'll be confidential.

-Njombe (Intervention)

One participant spoke in particular about the enrollment process at CTC being extremely lengthy, to the point of deterring her from enrolling into care previously.

I've once attended to the hospital before joining this [community ART] program. I wanted to start on ARVs. But they had such a long enrollment procedure... so I changed my mind.

-Njombe (Intervention) 


\section{Participants in both arms rarely missed their dose and knew the importance of adherence}

Qualitative findings support the finding that adherence was high in both arms. Participants in both arms seemed to understand the importance of adherence. Many spoke about the repeated messages around adherence they received from the providers. They understood the importance of taking ARVs daily and at the same time.

I believe taking these ARVs is my life, and I'll die if I stop. So that kind of thinking gives me strength to take them every day as if it's my life, my food.

-Njombe (Intervention)

We are being told that, using ARVs deactivates HIV, and activates the virus when we stop taking the meds, causing them to multiply as well. That's why we are advised to adhere to drugs on time. If it's at 8pm, or 9pm it should be constant.

-Mbeya (Comparison)

Almost all IDI participants reported that they are able to take their medications regularly and rarely forget to take their ARVs. A number indicated that their health was noticeably improved so they continue to take the medications regularly as instructed.

I have never forgotten my drugs, I feel like that's my life; even my kids have noticed how well I'm doing, and I thank God for this good progress.

-Mbeya (Comparison)

\section{FSWs in both arms reported similar barriers to adherence}

Despite high levels of adherence, participants in both arms spoke about factors that influenced them to miss some doses of ARVs. A big concern with taking medications was that others may learn about it. Their lifestyle sometimes made it challenging to take ARVs regularly. Some found it difficult to keep to their schedule when they were traveling.

It's normally hard for me to draw my ARVs out in front of my colleagues. Because two or more of us may be staying in one place; so I'm supposed to go to work and come back when they are not around and take my pills. Or else I wait till all my friends are not around and hide my drugs somewhere for later use-when it's time to take my drugs. So those are some of the challenges we face, it's kind of hard for us.

-Njombe (Intervention)

It [missing ARV dose] may hardly happen once in three months when I travel over a day, and I forget to take my pills.

-Mbeya (Comparison)

Participants in both arms also spoke about how it was initially difficult for them to take the ARVs, either because they were not used to a new routine or because of the initial side effects. However, 
once they became accustomed to the new routine or their body adjusted to the medications, they were able to take the ARVs regularly.

It was back then [when I started taking ARVs], when I was not used to taking them. I'm now used to them, I don't forget.

-Njombe (Intervention)

It's true, because the pills bring about drowsy feeling at first. That was a block on the road for me when I started using these drugs, so I was not used to them hence I stopped using them for a while.

-Mbeya (Comparison)

\section{Some aspects of service quality were perceived to be similar in both arms}

In both arms, participants for the most part spoke similarly about the perceived competence of the providers and client-provider interaction.

Perceived competence of providers: Although participants are not knowledgeable about clinical issues related to ART services to assess the competence of providers, they did perceive that their providers were competent and very knowledgeable about how to treat them for HIV. This was the case in both arms.

Yes, they are knowledgeable. I see them as professional nurses who know what they do. I don't see any differences from nurses in the hospitals. They test as the same way, and services are similar to hospitals.

-FSW, Njombe (Intervention)

They are well informed, because they usually teach us a bit each time we attend the clinic.

-FSW, Mbeya (Comparison)

Client-provider interactions: Participants in both arms were very satisfied with their interactions with the service providers. They felt that the providers spoke to them and treated them with respect.

They are friendly and that is why I said I never experienced any sort of bad thing. They are gentle and civilized, charming, and they don't segregate.

-FSW, Mbeya (Comparison)

Without telling lies, we have wonderful conversation with them.

-FSW, Mbeya (Comparison)

The service providers don't use offensive language around us, they are confidential.

-FSW, Njombe (Intervention) 


\section{Viral load testing was more efficient in the community-based ART intervention}

Although viral suppression was similar between the two arms at both midline and endline, qualitative findings suggest that those in the intervention arm were more likely to receive their viral load test results and know whether they were virally suppressed or not. Most of the participants in the comparison arm indicated that they often do not get their viral load test results back.

I like how they give my results back after taking blood samples from me. Leads me to know progress of my health, if I have high or low viral count.

-Njombe (Intervention)

Clients must check their HIV viral load and results could take up to two months. We may take our results while we go for refills, so I have not got my results yet.

-Mbeya (Comparison)

\section{Health-related behaviors, exposure, and satisfaction with ART services}

Table 6 shows the comparison of various health-related behaviors and satisfaction with ART services in the two arms at midline and endline.

\section{STI screening and testing}

At midline, approximately one-quarter had received an STI checkup during the previous three months; there was no difference by arm. At endline, those in the comparison arm were significantly more likely to have received an STI checkup compared to the intervention arm (43 percent versus 30 percent, $p<0.001$ ). At midline, around 10-14 percent were told to have an STI test in the previous three months; there was no difference by arm. At endline, a smaller percentage were told to have an STI test (less than 2 percent in both arms).

\section{Family planning}

A fairly high proportion (approximately 70-80 percent) indicated they used a modern family planning method at last sex with a client or non-paying sex partner at midline and endline; there was no difference by arm.

\section{Opportunistic infections (Ols)}

A significantly higher proportion were currently taking medications for Ols in the comparison group compared to the intervention group at midline (36 percent versus 14 percent, $p<0.001$ ) and at endline (61 percent versus 26 percent, $p<0.001)$.

\section{Viral load testing}

Participants at endline were asked if they received viral load testing in the previous six months. Testing was high in both arms; however, it was significantly higher in the intervention arm (92 percent versus 79 percent, $p<0.001$ ). 
Table 6 Comparisons of health-related behaviors and satisfaction with ART services at midline and endline by study arm

\begin{tabular}{|c|c|c|c|c|c|c|}
\hline & & Midline & & & Endline & \\
\hline & $\begin{array}{l}\text { Comparison } \\
\quad \mathrm{N}=253 \\
\%(n)\end{array}$ & $\begin{array}{l}\text { Intervention } \\
\begin{array}{l}\mathrm{N}=256 \\
\%(n)\end{array}\end{array}$ & p-value & $\begin{array}{l}\text { Comparison } \\
\mathrm{N}=262 \\
\%(n)\end{array}$ & $\begin{array}{l}\text { Intervention } \\
\quad \mathrm{N}=265 \\
\%(\mathrm{n})\end{array}$ & p-value \\
\hline $\begin{array}{l}\text { Received an STI checkup during } \\
\text { the past } 3 \text { months }\end{array}$ & $\begin{array}{l}27.3 \\
(69)\end{array}$ & $\begin{array}{l}28.9 \\
(74)\end{array}$ & 0.682 & $\begin{array}{l}42.8 \\
(112)\end{array}$ & $\begin{array}{c}29 . .8 \\
(79)\end{array}$ & $<0.001$ \\
\hline $\begin{array}{l}\text { Was told by provider to have an } \\
\text { STI test during the past } 3 \text { months }\end{array}$ & $\begin{array}{c}14.1 \\
(10 / 71)\end{array}$ & $\begin{array}{c}10.7 \\
(8 / 75)\end{array}$ & 0.53 & $\begin{array}{c}1.8 \\
(2 / 114)\end{array}$ & $\begin{array}{c}1.27 \\
(1 / 79)\end{array}$ & 0.787 \\
\hline $\begin{array}{l}\text { Used modern family planning } \\
\text { method the last time having sex } \\
\text { with a client or a non-paying } \\
\text { partner }\end{array}$ & $\begin{array}{c}71.9 \\
(182)\end{array}$ & $\begin{array}{l}71.9 \\
(184)\end{array}$ & 0.988 & $\begin{array}{l}82.8 \\
(217)\end{array}$ & $\begin{array}{l}76.2 \\
(202)\end{array}$ & 0.061 \\
\hline $\begin{array}{l}\text { Currently taking medicine to } \\
\text { prevent Ols }\end{array}$ & $\begin{array}{l}36.0 \\
(91)\end{array}$ & $\begin{array}{l}13.7 \\
(35)\end{array}$ & $<0.001$ & $\begin{array}{l}61.1 \\
(160)\end{array}$ & $\begin{array}{l}25.7 \\
(68)\end{array}$ & $<0.001$ \\
\hline $\begin{array}{l}\text { Tested for viral load (past } 6 \\
\text { months) }\end{array}$ & - & - & - & $\begin{array}{l}79.2 \\
(207)\end{array}$ & $\begin{array}{l}92.1 \\
(244)\end{array}$ & $<0.001$ \\
\hline $\begin{array}{l}\text { Talked to peer educator during } \\
\text { the past } 6 \text { months }\end{array}$ & $\begin{array}{l}53.4 \\
(135)\end{array}$ & $\begin{array}{l}99.6 \\
(255)\end{array}$ & $<0.001$ & $\begin{array}{c}41.2 \\
(108)\end{array}$ & $\begin{array}{l}95.5 \\
(253)\end{array}$ & $<0.001$ \\
\hline $\begin{array}{l}\text { Reported being "very satisfied" } \\
\text { with ART services during the last } \\
\text { ART visit }\end{array}$ & $\begin{array}{c}59.4 \\
(104 / 175)\end{array}$ & $\begin{array}{c}97.1 \\
(232 / 239)\end{array}$ & $<0.001$ & $\begin{array}{l}80.4 \\
(156)\end{array}$ & $\begin{array}{l}99.2 \\
(260)\end{array}$ & $<0.001$ \\
\hline
\end{tabular}

Notes: Both numerators and denominators are shown when only a subset of the sample have the data.

\section{Exposure to a peer educator}

Almost all participants in the intervention arms (99.6 at midline, and 96 percent at endline) reported having interactions with peer educators (past 6 months). This suggests a high level of intervention fidelity of the community-based ART program in Njombe, in which peer educators deliver adherence counseling services to FSWs at home, hotspots, or mobile HCT. Although Sauti HIV prevention and support teams were active in the Mbeya region during that same time period, a much lower proportion reported having interactions with peer educators (53 percent at midline and 41 percent at endline).

\section{Satisfaction with ART services}

Participants were asked how satisfied they were with the ART services at their last ART visit (a single item). Participants in the intervention arm were significantly more likely to indicate "very satisfied" compared to the comparison arm at midline (97 percent versus 59 percent, $p<0.001$ ) and at endline (99 percent versus 80 percent, $p<0.001$ ).

We also explored bivariate relationships between each of these outcomes and the following covariates: number of living children, income, educational level, experience of violence, time of 
HIV diagnosis, and HIV status disclosure. If the bivariate relationship between each co-variate and one of the outcomes was significant at $p<0.15$, that co-variate was adjusted for in the multivariate regression model.

\section{EFFECT OF THE INTERVENTION ON SEXUAL RISK AND VIOLENCE}

Table 7 presents the sexual risk behaviors of FSWs at baseline and endline (12-month followup) for each arm. In both arms, risk behaviors of FSWs with their non-paying partners improved significantly in both the comparison and intervention arms. Sex with non-paying partners declined significantly from baseline to endline in both arms (comparison: 44 percent to 28 percent; intervention: 71 percent to 56 percent). Condom use at last sex with a non-paying partner also increased significantly (comparison: 21 percent to 47 percent; intervention: 28 percent to 36 percent). Disclosure to their non-paying partner as well as knowing the status of their non-paying partner increased significantly in both groups.

Sexual risk behaviors with paying partners improved more in the intervention arm compared to the comparison group. Condom use at last sex act with a paying partner increased significantly for those in both the intervention arm (36 percent to 69 percent) and the comparison arm (46 percent to 58 percent). However, frequency of sex with a paying partner and being drunk at last sex with a paying partner decreased significantly in the intervention arm but not in the comparison arm.

There were significant decreases from baseline to endline only in the intervention arm in experience of physical (32 percent to 11 percent) and sexual (38 percent to 8 percent) violence. There were no significant decreases in these factors in the comparison arm; however, it should be noted that experience of violence was fairly low (less than 3 percent) at baseline in the comparison group.

Disclosure to anyone other than a health care provider increased significantly in both the intervention (36 percent to 83 percent) and the comparison (43 percent to 89 percent) arms.

Qualitative findings indicate the FSWs in both arms received messages around sexual risk reduction in the context of both preventing onward transmission as well as preventing another HIV infection (i.e., superinfection). They reported that providers gave them this counseling on a regular basis and that they also received condoms.

They just gave me condoms, and advise that I should be using them to avoid new infections. New infection could come up stronger, so I should just remain with my current infections.

-Njombe (Intervention)

They remind us a lot about use of condoms. Despite being careful and having condoms most of the time.... 
Table 7 Comparisons of HIV-related risk behaviors and violence at baseline and endline by study arm

\begin{tabular}{|c|c|c|c|c|c|c|}
\hline \multirow[t]{2}{*}{ Variable } & \multicolumn{3}{|c|}{ Comparison } & \multicolumn{3}{|c|}{ Intervention } \\
\hline & $\begin{array}{l}\text { Baseline } \\
N=308\end{array}$ & $\begin{array}{l}\text { Endline } \\
\mathrm{N}=262\end{array}$ & p-value & $\begin{array}{l}\text { Baseline } \\
\mathrm{N}=309\end{array}$ & $\begin{array}{l}\text { Endline } \\
\mathrm{N}=265\end{array}$ & p-value \\
\hline \multicolumn{7}{|l|}{ Non-paying sex partners } \\
\hline $\begin{array}{l}\text { Had sex with a non-paying } \\
\text { partner (past month) }\end{array}$ & $\begin{array}{l}43.8 \\
(135)\end{array}$ & $27.8(98)$ & 0.001 & $\begin{array}{l}71.2 \\
(220)\end{array}$ & $\begin{array}{l}56.2 \\
(149)\end{array}$ & 0.001 \\
\hline $\begin{array}{l}\text { Used a condom at last sex } \\
\text { with a non-paying partner } \\
\text { (past month) }\end{array}$ & $20.7(24)$ & $46.9(45)$ & 0.001 & $28.2(62)$ & $35.6(67)$ & 0.001 \\
\hline $\begin{array}{l}\text { During your last sex act, the } \\
\text { non-paying partner knew that } \\
\text { you were HIV positive }\end{array}$ & $8.9(12)$ & 34.4 (33) & 0.001 & $8.4(18)$ & $44.9(66)$ & 0.001 \\
\hline $\begin{array}{l}\text { During the last sex act, you } \\
\text { knew the status of your non- } \\
\text { paying partner }\end{array}$ & $2.9(4)$ & $20.8(20)$ & 0.001 & $5.9(207)$ & $17.7(26)$ & 0.001 \\
\hline \multicolumn{7}{|l|}{ Paying partners } \\
\hline $\begin{array}{l}\text { On average, had at least } 1 \\
\text { paying partner per day (past } \\
\text { month) }\end{array}$ & $13.3(41)$ & $10.3(18)$ & 0.340 & $\begin{array}{l}55.0 \\
(170)\end{array}$ & $11.9(28)$ & 0.001 \\
\hline $\begin{array}{l}\text { Used a condom at last sex } \\
\text { with a paying partner (past } \\
\text { month) }\end{array}$ & $\begin{array}{l}45.8 \\
(141)\end{array}$ & $57.6(151)$ & 0.005 & $\begin{array}{l}35.9 \\
(111)\end{array}$ & $\begin{array}{l}68.7 \\
(162)\end{array}$ & 0.001 \\
\hline $\begin{array}{l}\text { Self-reported being drunk } \\
\text { during last sex with a paying } \\
\text { partner }\end{array}$ & $13.0(40)$ & $10.3(27)$ & 0.322 & $25.2(78)$ & $17.7(47)$ & 0.03 \\
\hline \multicolumn{7}{|l|}{ All FSWs } \\
\hline $\begin{array}{l}\text { Experienced physical violence } \\
\text { (past } 6 \text { months) }\end{array}$ & $2.6(50)$ & $3.1(50)$ & 0.743 & $31.7(98)$ & $10.6(28)$ & 0.001 \\
\hline $\begin{array}{l}\text { Experienced sexual violence } \\
\text { (past } 6 \text { months) }\end{array}$ & $1.6(5)$ & $0.4(1)$ & 0.148 & $\begin{array}{c}38.2 \\
(118)\end{array}$ & $8.3(22)$ & 0.001 \\
\hline $\begin{array}{l}\text { Mobility (traveled outside of } \\
\text { the region to sell sex; past } 6 \\
\text { months) }\end{array}$ & $10.4(32)$ & $9.2(24)$ & 0.623 & $\begin{array}{l}35.6 \\
(110)\end{array}$ & $33.2(88)$ & 0.548 \\
\hline $\begin{array}{l}\text { HIV disclosure to someone } \\
\text { other than a health care } \\
\text { provider }\end{array}$ & $43.1(25)$ & $\begin{array}{l}89.4 \\
(210)\end{array}$ & 0.001 & 35.9 (14) & $\begin{array}{l}82.6 \\
(219)\end{array}$ & 0.001 \\
\hline
\end{tabular}

Notes: All FSW participants reported on average, each had at least 1 paying client per day 


\section{LEVELS OF HIV-RELATED STIGMA}

Table 8 compares externalized and internalized HIV-related stigma items between comparison and intervention arms at midline and endline.

\section{Externalized stigma}

In both arms at midline and endline, a very small proportion of FSWs reported experiencing externalized stigma (less than 10 percent). The only exception was with people gossiping about the person because of HIV. This was reported to be more common than the other forms of externalized stigma and it was significantly higher in the intervention arm at midline (62 percent versus 38 percent, $p=0.019)$ and at endline (10 percent versus 2 percent, $p<0.001$ ).

\section{Internalized stigma}

Feelings of internalized stigma were more common than externalized stigma in both arms. Slightly over one-half in both arms and at both time points indicated that it was difficult to tell others about their HIV infection. There was no difference by study arm. Feelings of being dirty, guilt, and shame because of HIV positivity were felt by approximately one-quarter to one-third of participants at midline and endline. These feelings were more common among FSWs in the comparison arm than in the intervention arm at both midline and endline. The most commonly felt manifestation of internalized stigma was that they wanted to hide their HIV status from others; this was higher among those in the intervention group as opposed to the comparison group at midline (70 percent versus 57 percent, $p=0.002$ ) and at endline ( 76 percent versus 59 percent, $p<0.001$ ). 
Table 8 Levels of externalized and internalized stigma at midline and endline by study arm

\begin{tabular}{|c|c|c|c|c|c|c|}
\hline & \multicolumn{3}{|c|}{ Midline } & \multicolumn{3}{|c|}{ Endline } \\
\hline & $\begin{array}{c}\text { Comparison } \\
n=256 \\
\%(n)\end{array}$ & $\begin{array}{l}\text { Intervention } \\
\qquad \begin{array}{c}n=253 \\
\%(n)\end{array}\end{array}$ & p-value & $\begin{array}{c}\text { Comparison } \\
\begin{array}{c}n=262 \\
\%(n)\end{array}\end{array}$ & $\begin{array}{l}\text { Intervention } \\
n=265 \\
\%(n)\end{array}$ & p-value \\
\hline \multicolumn{7}{|l|}{ Externalized } \\
\hline $\begin{array}{l}\text { Excluded from family } \\
\text { activities (cooking, eating } \\
\text { together, sleeping in the } \\
\text { same room) because of } \\
\text { HIV }\end{array}$ & $1.2(3)$ & $4.3(245)$ & 0.032 & $1.5(4)$ & $2.6(7)$ & 0.371 \\
\hline $\begin{array}{l}\text { Excluded from social } \\
\text { gatherings or activities } \\
\text { (parties, clubs, wedding, } \\
\text { funerals) because of HIV }\end{array}$ & $1.2(3)$ & $2.0(5)$ & 0.486 & $0.4(1)$ & $1.1(3)$ & 0.321 \\
\hline $\begin{array}{l}\text { Excluded from religious } \\
\text { activities or places of } \\
\text { worship because of HIV }\end{array}$ & $0.4(1)$ & $1.6(4)$ & 0.182 & $10.4(1)$ & $1.2(3)$ & 0.321 \\
\hline $\begin{array}{l}\text { Gossiped about because } \\
\text { of HIV }\end{array}$ & 37.8 (31) & $62.2(51)$ & 0.019 & $1.5(4)$ & $10.2(27)$ & $<0.001$ \\
\hline $\begin{array}{l}\text { Rejected by a sexual } \\
\text { partner because of HIV }\end{array}$ & $4 . .0(10)$ & $4.7(12)$ & 0.684 & $1.2(3)$ & $2.6(7)$ & 0.208 \\
\hline $\begin{array}{l}\text { Treated unfairly/or being } \\
\text { discriminated against by } \\
\text { a health care provider } \\
\text { because of HIV }\end{array}$ & $0(0)$ & $0.8(2)$ & 0.159 & $0.8(2)$ & $0(0)$ & 0.154 \\
\hline \multicolumn{7}{|l|}{ Internalized } \\
\hline $\begin{array}{l}\text { It is difficult to tell people } \\
\text { about my HIV infection. }\end{array}$ & $56.1(142)$ & 60.6 (155) & 0.312 & 60.7 (159) & 60.8 (161) & 0.987 \\
\hline $\begin{array}{l}\text { Being HIV positive makes } \\
\text { me feel dirty }\end{array}$ & $21.0(53)$ & 9.0 (23) & $<0.001$ & $24.4(64)$ & $17.7(47)$ & 0.06 \\
\hline $\begin{array}{l}\text { I feel guilty that I am HIV } \\
\text { positive }\end{array}$ & $37.9(96)$ & $18.8(48)$ & $<0.001$ & $37.4(98)$ & $21.1(56)$ & $<0.001$ \\
\hline $\begin{array}{l}\text { I am ashamed that I am } \\
\text { HIV positive }\end{array}$ & $30.0(76)$ & $19.8(50)$ & 0.006 & $33.6(88)$ & $26.4(70)$ & 0.072 \\
\hline $\begin{array}{l}\text { I sometimes feel worthless } \\
\text { because I am HIV positive }\end{array}$ & $22 . .5(57)$ & $21.1(54)$ & 0.695 & $27.9(73)$ & $25.3(67)$ & 0.053 \\
\hline $\begin{array}{l}\text { I hide my HIV status from } \\
\text { others }\end{array}$ & 56.5 (143) & 69.9 (179) & 0.002 & $59.2(155)$ & 75.9 (201) & $<0.001$ \\
\hline
\end{tabular}




\section{DISCUSSION}

To improve rates of ART initiation and retention among FSWs, we designed and piloted an innovative, community-based ART delivery model that was built on an existing mobile HIV prevention service platform, specifically CBHTC+ services. This model is the first being implemented among FSWs in Tanzania combining aspects of both service integration and decentralization (bringing services to the community and incorporating treatment into testing services).

As baseline findings indicate, that there is a clear need for interventions to improve timely HIV diagnosis and linkage to treatment. Baseline findings clearly identified a gap in HIV testing and treatment because one-third learned about their HIV-positive status only at study enrollment. Additionally, among FSWs who had known their status for more than a month, half had not registered in care. A community-based ART program may serve as an important strategy in closing the HIV care and treatment gap for FSWs. In fact, findings from this study demonstrate that ART provision through a community-based distribution mechanism can lead to higher ART initiation and better retention.

ART initiation was significantly associated with the community-based intervention. This is likely due to the innovative $\mathrm{CBHTC}+$ team service model, which by design was actively involved in the recruitment, testing/retesting (if necessary), enrollment into ART, and ART initiation of the cohort participants by peer educators. While those in the intervention arm received immediate adherence counseling and a one-month ARV supply, those in the comparison arm received a passive referral to the government-designated CTC facility (though they could be escorted by Sauti peer educators). As our qualitative findings indicated, the CTC facilities are perceived to have lengthy enrollment processes and long waits. FSWs were also motivated to join the communitybased ART program as it would save them time and travel costs associated with going to distant clinics. A qualitative study conducted among HIV-positive patients in Malawi who were part of a community ART group, whereby members took turns collecting ARVs for group members, found that reduced frequency of clinic visits and associated transportation costs were important in facilitating ART access (Pellecchia et al. 2017).

Our findings also indicated that lower internalized stigma was independently associated with ART initiation. Internalized stigma was fairly common among both study arm participants, although for the most part it was more common in the comparison arm. Studies have shown that internalized stigma can manifest in a variety of ways, including low self-esteem, self-isolation, shame, withdrawal from seeking health services, and depression (Rael and Hampanda 2016; Visser et al. 2008; Wingood et al. 2008), which in turn can impact HIV treatment-seeking behaviors (Sabapathy et al. 2017). This suggests that ART services need to adopt strategies to help patients develop a healthy self-perception in relation to their HIV diagnosis and cope psychologically.

This study also showed that those receiving community-based ART services had higher retention rates (i.e., self-reported current ARV usage) at both the 6- and 12-month follow-up visits and retention was independently associated with the community-based intervention. Retention in the 
community-based arm was nearly 100 percent at both 6 and 12 months. However, longer term retention at 12 months in the comparison arm was considerably lower than the intervention arm. The intervention retention rate in this study is better than the self-reported percentage retention rate among HIV-positive women who know their status (93 percent) reported in the 2016-2017 Tanzania HIV Impact Survey (Government of Tanzania, TACAIDS, and ZAC 2018) and the retention rate among females reported from the Tanzania national service data (approximately 80 percent depending on cohort year) (Mee et al. 2019). In fact, the 12-month retention rate in the comparison arm in this study is similar to the 12-month retention rate reported in the study based on the national service data in Tanzania (Mee et al. 2019). The retention rate in this study's intervention group is also similar to rates found in other countries implementing communitybased ART, particularly those supported by LINKAGES, a USAID-funded project implemented by FHI 360, where the program provided active referrals and support for FSWs to access ART (e.g., through community-based outreach, ART provision at drop-in centers, and support from peer educators and case managers) (LINKAGES 2018). The 12-month retention rate in the comparison arm (77 percent) likely reflects the numerous structural barriers faced by FSWs in accessing facility-based ART services as reported by other studies in Africa (Mountain et al. 2014; Nakanwagi et al. 2016; Scorgie et al. 2013). While retention in the intervention arm remained steady from 6 to 12 months in this study, the retention in the comparison arm decreased considerably by 12 months. The declining retention rate over time is not surprising and is seen in the national service data as well, which reported retention among females declining from 81 percent at 12 months to 58 percent at 24 months to 47 percent at 36 months (Mee et al. 2019).

Our findings indicated that the community-based ART intervention did not affect adherence to ART. However, adherence was fairly high in both study arms. Our qualitative findings indicated that adherence was a function of individual-level factors such travel and unintentional disclosure of their HIV status to others. This suggests that adherence counseling needs to address how adherence can be maintained during travel and how medications can be taken discreetly. Further, counseling can also facilitate disclosure of HIV status to others who may be close to the patients so that unintentional disclosure would not be an issue.

Although viral suppression was not affected by the intervention, viral suppression was achieved by a high proportion of FSWs who initiated ART (approximately 80 percent). This is slightly lower than the viral suppression rate of 89 percent among HIV-positive females who self-reported current ART use in the general population (Government of Tanzania, TACAIDS, and ZAC 2018). This may be due to lower adherence among FSWs compared to the general population given the greater challenges and barriers FSWs face in accessing ART services (Mountain et al. 2014; Lancaster et al. 2016; Nakanwagi et al. 2016; Scorgie et al. 2013). Although viral suppression rates were similar between the two arms, the intervention fared better in terms of testing patients for viral load and letting them know their viral load results. ART programs must improve their viral load testing coverage in order to diagnose treatment failure. Additionally, in this era of the " $U=U$ " messaging (undetectable equals untransmissible), it is even more important for individuals to know their viral load status in order to make informed decisions about their sexual behaviors.

Baseline data showed more than half of FSWs had a non-paying sex partner, and less than onethird used a condom at last sex with paying and non-paying clients, which suggests potentially high levels of HIV transmission. However, it was encouraging to see that condom use with 
paying clients and with steady partners increased significantly in both arms after enrollment into the study. This is not surprising given that FSWs in both arms indicated they received regular counseling messages on the importance of condom use to prevent transmission. Despite concerns about risk compensation after initiating ART, there is evidence from previous studies that unprotected sex decreases after ART initiation (Venkatesh et al. 2010; Venkatesh, Flanigan, and Mayer 2011; Luchters et al. 2008) including among FSWs (McClelland et al. 2011; McClelland et al. 2010; Pearson et al. 2011).

Disclosure to non-paying steady partners also increased in both arms. Disclosure counseling is a service that all FSWs receive when they test HIV positive through the Sauti CBHTC+ services regardless of which arm FSWs were in. HIV status disclosure may help explain the increased use of condoms, particularly with non-paying steady partners. Previous studies have found that unsafe sex is associated with non-disclosure and reduced sexual transmission risk behaviors have been associated with disclosure (Luchters et al. 2008; Pearson et al. 2011; Loubiere et al. 2009; Simbayi et al. 2007; Wong et al. 2009). Although disclosure to steady partners increased in both arms, it still remained low (less than 50 percent). It will be important to ensure that HIV testing programs continue to facilitate disclosure to partners. Not only does disclosure facilitate safer sex, but it is an opportunity to test sex partners for HIV and facilitate entry into treatment if found positive. Although disclosure of HIV status was not found to be associated with any of the treatment outcomes, previous studies have reported disclosure to be associated with improved treatment outcomes (Ostermann et al. 2015; Stirratt et al. 2006).

Experience of violence is always a concern with disclosure to sexual partners. Although we do not know the context or the consequences of the disclosure to steady partners, there was no evidence in our findings of increased physical or sexual violence from baseline to endline.

\section{LIMITATIONS}

These findings should be viewed in light of the study limitations. First, treatment outcomes were self-reported, and thus participants may have responded in the favorable direction due to social desirability. Second, the two regions were not randomly selected, which reduced the comparability of the two arms. The analysis controlled for differences in demographics and other factors that might affect the outcome (time since diagnosis and internalized stigma); however, there were substantial differences in participant characteristics across sites and the analysis cannot control for other unknown factors. Although the two regions differed on several factors (e.g., risk behaviors, experience of violence), these variables were not associated with the outcome of interest. It should, however, be noted that a strength of selecting these two sites for the study is that the intervention was implemented in the "real-world" setting as opposed to a strict controlled setting in which generalizability would be reduced. The intervention was implemented in a way that it would typically be implemented outside of the study setting, thus increasing the generalizability of the findings. 


\section{CONCLUSIONS}

This pilot represented an opportunity to test an innovative idea that meets the unique and different needs of FSW, a stigmatized and vulnerable population, and that reduces barriers in accessing care such as long distances to clinics, long waiting times at clinics, privacy concerns, and opportunistic costs.

The study findings dispel some concerns about negative treatment outcomes, managing adverse events, and quality of care raised initially by NACP officials. We found community-based ART using a mobile and home-based platform led by a team of clinicians and peer educators resulted in increased initiation and retention in ART, reduced sexual risk behaviors, and improved service quality.

The average annual ART-service related cost per FSW was US\$440, which is consistent with findings from recent studies on treatment costs in neighboring countries. For example, data from South Africa indicated that the cost of treatment was US $\$ 300$ per patient per year. A multicountry study by the Clinton Health Access Initiative estimated annual treatment costs of US\$ 186 in Malawi, US\$232 per year in Rwanda, US\$ 682 in South Africa, and US\$278 in Zambia.

Although community-based ART delivery increases ART initiation and retention, once initiated, adherence and viral suppression rates are similar to the standard of care through CTCs. This indicates that the greatest gain from the community-based ART is getting FSWs initiated on ART and retained in care. While FSWs perceived many aspects of the quality of services to be similar between services through CTC and the community-based ART, FSWs were more satisfied with the ART services they received through the community-based ART services and indicated a strong liking for several key aspects of the community-based ART model. Specifically, they liked the convenience, time and cost-saving features, and the confidentiality it provides, which may prove key in fostering long term retention in care and viral suppression. 


\section{RECOMMENDATIONS}

- Given the effectiveness of this pilot community-based ART delivery model on key ART treatment outcomes, sexual risk, and service quality, we highly recommend the government of Tanzania to continue and expand this approach. In addition, our pilot has proved that implementation of this innovative approach is highly feasible, acceptable, and adaptable.

- While community-based ART may have positively improved ART treatment outcomes, we are not certain which aspects of the community-based program (such as service decentralization, flexible schedule visits, supportive and non-stigmatizing ART care, or reduced opportunistic costs) may have contributed to the overall impact. In addition, this was a relatively short-term study and, therefore, understanding the long-term impact of this strategy is important. After the study ended, Sauti, with strong support from the NACP, has been able to continue providing community-based ART services to the original cohort participants. We recommend careful monitoring of these patients in order to measure longer-term impact of this strategy.

- Data showed a high prevalence of sexual violence as well as a decrease after one year, particularly in the intervention arm. The continuation of Sauti's GBV interventions, such as sex worker empowerment, community mobilization to respond to violence, and referrals to GBV services, are critical and may have contributed to this effect. We recommend further monitoring of such GBV interventions among FSWs to measure this aspect.

- We also recommend that strategies to reduce internalized HIV stigma be an integral part of HIV services. Such strategies include linkage to peer educators/supporters who understand their lifestyle, peer support groups, educating oneself/others about HIV, viewing HIV as a manageable condition, and controlled and pre-emptive HIV disclosure (Paudel and Baral 2015; Rael et al. 2017; Rao et al. 2012; Stangl et al. 2013). These strategies can help patients adopt a healthier self-perception and cope with a positive HIV diagnosis.

- Additionally, ART providers should facilitate HIV disclosure, especially to steady partners, during patients' routine visits and adherence counseling. This may eliminate fears of possible negative consequences if one discloses their HIV status.

- Strategies are needed to improve viral load testing coverage. ART services must improve their processes of viral load testing to ensure that patients are tested as well as learn their test results. 


\section{REFERENCES}

Bemelmans, M., et al. 2014. "Community-supported models of care for people on HIV treatment in sub-Saharan Africa," Tropical Medicine \& International Health 19(8): 968-77. doi: 10.1111/tmi.12332

Government of Tanzania, Tanzania HIV Impact Sur Tanzania Commission for AIDS (TACAIDS), Zanzibar AIDS Commission (ZAC). 2018. Tanzania HIV Impact Survey (THIS) 2016-2017: final report. Dar es Salaam, Tanzania: Government of Tanzania.

Govindasamy, D. et al. 2014. "Interventions to improve or facilitate linkage to or retention in pre-ART (HIV) care and initiation of ART in low- and middle-income settings-a systematic review," Journal of the International AIDS Society 17: 9032. doi: 10.7448/IAS.17.1.19032

Kalichman, S.C. et al. 2009. "Measuring AIDS stigmas in people living with HIV/AIDS: the Internalized AIDSRelated Stigma Scale,” AIDS Care 21(1): 87-93. doi: 10.1080/09540120802032627

Konate, I. et al. 2011. "Linking HIV prevention and care for community interventions among high-risk women in Burkina Faso--the ARNS 1222 'Yerelon' cohort," Journal of Acquired Immune Deficiency Syndromes 57(Suppl 1): S50-4. doi: 10.1097/QAI.0b013e3182207a3f

Lancaster, K.E. et al. 2016. "The HIV care continuum among female sex workers: a key population in Lilongwe, Malawi,” PLoS One 11(1): e0147662. doi: 10.1371/journal.pone.0147662

LINKAGES. Accelerating the implementation and scale-up of comprehensive programs for HIV prevention, diagnosis, treatment and care for key Populationsp: LINKAGES approach and lessons learned. 4 September 2018]; Available from: https://www.fhi360.org/sites/default/files/media/documents/resource-linkagesaccelerating-implementation.PDF.

Loubiere, S. et al. 2009. "HIV disclosure and unsafe sex among HIV-infected women in Cameroon: results from the ANRS-EVAL study," Social Science \& Medicine 69(6): 885-91. doi: 10.1016/j.socscimed.2009.05.044

Luchters, S. et al. 2008. "Safer sexual behaviors after 12 months of antiretroviral treatment in Mombasa, Kenya: a prospective cohort," AIDS Patient Care STDs 22(7): 587-94.

McClelland, L. et al. 2011. "Understanding the context of HIV risk behavior among HIV-positive and HIV-negative female sex workers and male bar clients following antiretroviral therapy rollout in Mombasa, Kenya," AIDS Education and Prevention 23(4): 299-312.

McClelland, R.S., et al. 2010. "Treatment with antiretroviral therapy is not associated with increased sexual risk behavior in Kenyan female sex workers," AIDS 24(6): 891-7.

Mee, P. et al. 2019. "Changes in patterns of retention in HIV care and antiretroviral treatment in Tanzania between 2008 and 2016: an analysis of routinely collected national programme data," Journal of Global Health 9(1): 010424. doi: 10.7189/jogh.09.010424

Ministry of Health and Social Welfare, National AIDS Control Programme (Tanzania). 2014a. Consensus Estimates on Key Population Size and HIV Prevalence in Tanzania. Dar Es Salaam, Tanzania: Ministry of Health and Social Welfare.

Ministry of Health and Social Welfare, National AIDS Control Programme (Tanzania). 2014b. HIV and STI Biological and Behavioral Survey, 2013-a study of female sex workers in seven regions: Dar es Salaam, Iringa, Mbeya, Mwanza, Shinyanga, Tabora, and Mara. Dar Es Salaam, Tanzania: Ministry of Health and Social Welfare.

Mountain, E. et al. 2014. "Antiretroviral therapy uptake, attrition, adherence and outcomes among HIV-infected female sex workers: a systematic review and meta-analysis," PLoS One 9(9): e105645. doi: 10.1371/journal. pone.0105645

Mwai, G.W. et al. 2013. "Role and outcomes of community health workers in HIV care in sub-Saharan Africa: a systematic review," Journal of the International AIDS Society 16: 18586. doi: 10.7448/IAS.16.1.18586

Nakanwagi, S., et al. 2016. "Facilitators and barriers to linkage to HIV care among female sex workers receiving HIV testing services at a community-based organization in periurban Uganda: a qualitative study," Journal of Sexually Transmitted Diseases 2016: 7673014. doi: 10.1155/2016/7673014 
Ostermann, J. et al. 2015. "HIV serostatus disclosure in the treatment cascade: evidence from Northern Tanzania," AIDS Care 27(Suppl 1): 59-64. doi: 10.1080/09540121.2015.1090534

Paudel, V. and K.P. Baral. "Women living with HIV/AIDS (WLHA), battling stigma, discrimination and denial and the role of support groups as a coping strategy: a review of literature," Reproductive Health 12: 53. doi: 10.1186/ s12978-015-0032-9

Pearson, C.R. et al. 2011. "Change in sexual activity 12 months after ART initiation among HIV-positive Mozambicans," AIDS and Behavior 15(4): 778-87. doi: 10.1007/s10461-010-9852-3

Pellecchia, U. et al. 2017. "We are part of a family." Benefits and limitations of community ART groups (CAGs) in Thyolo, Malawi: a qualitative study," Journal of the International AIDS Society 20(1): 21374. doi: 10.7448/ IAS.20.1.21374

Rael, C.T. and K. Hampanda. 2016. "Understanding internalized HIV/AIDS-related stigmas in the Dominican Republic: a short report," AIDS Care 28(3): 319-24. doi: 10.1080/09540121.2015.1095277

Rael, C.T. et al. 2017. "Identifying strategies to cope with HIV-related stigma in a group of women living with HIV/ AIDS in the Dominican Republic: a qualitative study," AIDS and Behavior 21(9): 2589-2599. doi: 10.1007/ s10461-016-1654-9

Rao, D. et al. 2012. "Feasibility, acceptability, and preliminary efficacy of the unity workshop: an internalized stigma reduction intervention for African American women living with HIV," AIDS Patient Care and STDs 26(10): 614-20.

Research to Prevention (R2P). 2013. "Strategic assessment to define a comprehensive response to HIV in Iringa, Tanzania," Research Brief Female Sex Workers. Available from: http://www.jhsph.edu/research/centers-andinstitutes/research-to-prevention/publications/iringa/Iringa-FSW-brief-final.pdf.

Sabapathy, K. et al. 2017. "Predictors of timely linkage-to-ART within universal test and treat in the HPTN 071 (PopART) trial in Zambia and South Africa: findings from a nested case-control study," Journal of the International AIDS Society 20(4). doi: 10.1002/jia2.25037

Schwartz, S. et al. 2017. "Engagement in the HIV care cascade and barriers to antiretroviral therapy uptake among female sex workers in Port Elizabeth, South Africa: findings from a respondent-driven sampling study," Sexually Transmitted Infections 93(4): 290-296. doi: 10.1136/sextrans-2016-052773

Scorgie, F. et al. 2013. “'We are despised in the hospitals': sex workers' experiences of accessing health care in four African countries," Culture, Health \& Sexuality 15(4): 450-65. doi: 10.1080/13691058.2012.763187

Sharma, M. et al. 2015. "Systematic review and meta-analysis of community and facility-based HIV testing to address linkage to care gaps in sub-Saharan Africa," Nature 528(7580): S77-85. doi: 10.1038/nature16044

Simbayi, L.C. et al. 2007. "Disclosure of HIV status to sex partners and sexual risk behaviours among HIV-positive men and women, Cape Town, South Africa," Sexually Transmitted Infections 83(1): 29-34.

Somi, G. et al. 2012. "Low mortality risk but high loss to follow-up among patients in the Tanzanian national HIV care and treatment programme," Tropical Medicine and International Health 17(4): 497-506. doi: 10.1111/j.1365-3156.2011.02952.x

Stangl, A.L. et al. 2013. "A systematic review of interventions to reduce HIV-related stigma and discrimination from 2002 to 2013: how far have we come?," Journal of the International AIDS Society 16(3 Suppl 2): 18734. doi: 10.7448/IAS.16.3.18734

Stirratt, M.J. et al. 2006. "The role of HIV serostatus disclosure in antiretroviral medication adherence," AIDS and Behavior 10(5): 483-93.

Suthar, A.B. et al. 2013. "Towards universal voluntary HIV testing and counselling: a systematic review and meta-analysis of community-based approaches," PLoS Medicine 10(8): e1001496. doi: 10.1371/journal. pmed.1001496

Tanzania Commission for AIDS (TACAIDS), et al. 2013. Tanzania HIV/AIDS and Malaria Indicator Survey $2011-$ 12. Dar es Salaam, Tanzania: TACAIDS, ZAC, NBS, OCGS, and ICF International.

Tomori, C. et al. 2014. "Barriers and facilitators of retention in HIV care and treatment services in Iringa, Tanzania: the importance of socioeconomic and sociocultural factors," AIDS Care 26(7): 907-13. doi: 10.1080/09540121.2013.861574 
Venkatesh, K.K. et al. 2010. "Decreased sexual risk behavior in the era of HAART among HIV-infected urban and rural South Africans attending primary care clinics," AIDS 24(17): 2687-96. doi: 10.1097/ QAD.0b013e32833e78d4

Venkatesh, K.K., T.P. Flanigan, and K.H. Mayer. 2011. "Is expanded HIV treatment preventing new infections? Impact of antiretroviral therapy on sexual risk behaviors in the developing world," AIDS 25(16): 1939-49. doi: 10.1097/QAD.0b013e32834b4ced

Visser, M.J. et al. 2008. "Development of parallel scales to measure HIV-related stigma," AIDS and Behavior 2008. 12(5): 759-71. doi: 10.1007/s10461-008-9363-7

Wingood, G.M. et al. 2008. "HIV stigma and mental health status among women living with HIV in the Western Cape, South Africa," South African Journal of Science 104(5-6): 237-240.

Wong, L.H. et al. 2009. "Test and tell: correlates and consequences of testing and disclosure of HIV status in South Africa (HPTN 043 Project Accept)," Journal of Acquired Immune Deficiency Syndromes 50(2): 215-22.

World Health Organization, United Nations Population Fund, Joint United Nations Programme on HIV/AIDS, Global Network of Sex Work Projects, The World Bank. 2013. Implementing Comprehensive HIV/STI Programmes with Sex Workers: practical approaches from collaborative interventions. Geneva: World Health Organization.

World Health Organization. 2014. Consolidated Guidelines on HIV Prevention, Diagnosis, Treatment and Care for Key Populations. Geneva: World Health Organization. 


\section{APPENDIX}

\section{COMPARISON OF PARTICIPANTS LTFU AND PARTICIPANTS REMAINING IN THE STUDY AT THE 6- AND 12-MONTH FOLLOW-UP VISIT BY STUDY ARM}

(Note that being LTFU from the study does not mean that the participants are LTFU from the treatment) 


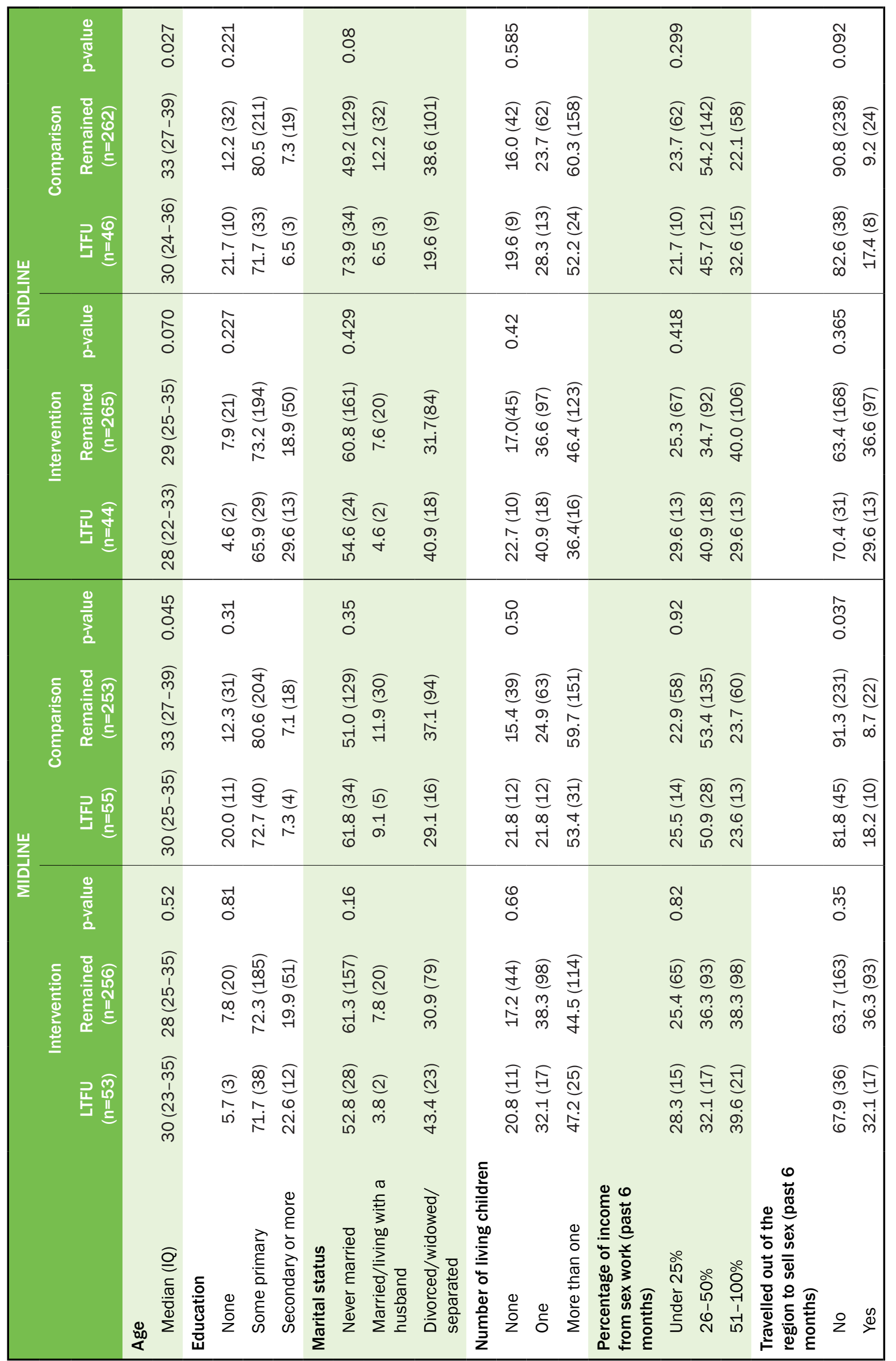


Project SOAR

Population Council 4301 Connecticut Ave, NW,

Suite 280

Washington, D.C. 20008 USA

Tel: +1 2022379400

Fax: +1 2022378410

Ideas. Evidence. Impact.

projsoar.org 